\title{
The Unexpected Consequences of Generic Entry.*
}

\author{
Micael Castanheira ${ }^{\dagger} \quad$ Carmine Ornaghi $^{\ddagger} \quad$ Georges Siotis $^{\S}$
}

September 18, 2019

\begin{abstract}
Generic drugs are sold at a fraction of the original brand price. Yet, generic entry typically produces a drop in the quantity market share of the molecule losing exclusivity. This effect is economically and statistically significant for a large dataset covering hundreds of prescription drugs sold in the US during the period 1994Q1-2003Q4. This paper proposes the first systematic analysis of what appears to be a market anomaly.

We propose a model to characterize the market equilibrium before and after generic entry. We identify precise conditions under which entry reduces the quantity market share of the molecule. Intriguingly, this is more likely to occur when the remaining patent-protected molecules feature low horizontal differentiation. We test this and other theoretical predictions of the model and find they are validated empirically.
\end{abstract}

JEL Classification: D22, I11, L13

Keywords: Non-Price competition, Pharmaceutical industry, Generic entry, Consumer choice

*This paper is dedicated to the memory of Maria-Ángeles de Frutos, who passed away just after completing a closely related paper. The genesis of this paper owes a lot to her insights and enthusiasm. We would like to thank two anonymous referees, the Editor, Laurent Bouton, Guilhem Cassan, Christopher Cotton, Raffaele Fiocco, Michel Goldman, Margaret Kyle, Patrick Legros, Alessandro Lizzeri, Laurent Mathevet, Jacopo Perego, Régis Renault, Patrick Rey, Pablo Querubin, Tobias Salz, Fiona Scott Morton, Denni Tommasi, and Philippe Weil for their helpful comments, as well as seminar participants at Oxford University, ECARES, i3h, the Paris School of Economics, Queen's University, Universidad Carlos III, Université de Cergy-Pontoise, Université de Lausanne, EARIE2016, and CRETE2016.

${ }^{\dagger}$ ECARES (Université Libre de Bruxelles - SBS-EM) and CEPR. Micael Castanheira is "Directeur de recherche" FRS-FNRS and gratefully acknowledges their financial support.

${ }^{\ddagger}$ University of Southampton

$\S$ Universidad Carlos III de Madrid and CEPR. Georges Siotis gratefully acknowledges the financial support from the Ministerio Economía y Competitividad (Spain) grants Beca I3 2006/04050/011, ECO2015-65204-P, MDM 2014-0431, and Comunidad de Madrid grant MadEco-CM (S2015/HUM-3444). 


\section{Introduction}

The growing costs of health care and pharmaceutical treatments often make newspaper headlines. High hopes are generally put on the market penetration of generics to limit ballooning drug prices. The results have been mixed: as we detail in this paper, generics indeed appear to be very effective competitors against molecules that experience Loss of Exclusivity (LoE). However, they typically fail to dent the position of drugs that remain on patent. As we show below (see Figure 1, p.6) at least until 2003, generic entry was associated with a drop in the quantity market share of the genericized (and thus cheaper) molecule. Still today, the availability of generics fails to dampen overall expenditure growth in the US, a country where drug prices are primarily determined by competitive interaction (see e.g. Crow, Jan. 4th, 2018). In that context, the recent record number of generics approval by the Federal Drug Administration (FDA) praised by The Economist is welcome, but unlikely to put a lid on prices. ${ }^{1}$ This suggests that the market wide effects of generic competition are poorly understood.

A central characteristic of the pharmaceutical industry is the unique combination of high investments in research and development and in promotion. ${ }^{2}$ While R\&D is the driver of market entry and of the differentiation between treatments, it is sunk by the time of generic entry, in contrast to promotional effort. Once on the market, a firm that wants to gain market share must either reduce its price or intensify its promotion effort. The process of approaching doctors to tout the virtues of a treatment is known as detailing. For large players, detailing and other forms of promotion represent $15 \%$ to $20 \%$ of total sales, about the same as R\&D. Also, detailing was a still relatively unregulated activity in the 1990s and early $2000 \mathrm{~s},{ }^{3}$ which offers a unique opportunity to study the broader question of how promotion

\footnotetext{
${ }^{1}$ The Economist, March 24th, 2018, "Getting medicines to market faster."

${ }^{2}$ The pharmaceutical industry is indeed a particular one. In the Oxford Handbook of the Biopharmaceutical Industry, Harrington (2012) estimates the R\&D to be at $17.9 \%$ of total net sales for the period 2001-2005, and Kenkel and Mathios (2012) report that the advertising-to-sales ratio was $18 \%$ in 2005 in the U.S. As points of comparison, they highlight that, in 2010, advertising stood at $4.5 \%$ of total net sales for General Motors (a car producer), 9.5\% for Anheuser Busch (a beer producer) and 10.8\% for Kellogg (breakfast cereals). The figures are typically smaller for most other R\&D-intensive industries. For instance, in 2013, Apple spent 3\% of its total net sales on R\&D and $0.4 \%$ on advertising (Apple 2013: 10-K SEC submission).

${ }^{3}$ The first code of conduct of the Pharmaceutical Research and Manufacturers of America (PhRMA) took effect in July 2002. Direct to Consumers Advertising (DTCA) was still in its infancy.
} 
affects competition in the pharmaceutical industry.

The model abstracts from the R\&D decision and focuses on the period around the loss of exclusivity (LoE) that triggers generic entry. We distinguish three phases: (1) before generic entry, two firms, $A$ and $B$, have a monopoly on their own molecule. Doctors seeking a treatment for their patient are thus facing a differentiated duopoly. (2) One of the two molecules, say $A$, loses exclusivity. We model this as a switch toward perfect competition for market segment $A$, while firm $B$ retains exclusivity. We call this an asymmetric competition shock. (3) The third phase is when also $B$ loses exclusivity, leading to perfect competition for both molecules. We derive the market equilibrium in each of these three phases and identify three main results that are important to understand the effects of generic entry - the changes between phase 1 and phase 2 in the model.

First, generic competition for $A$ allows $B$ to increase its price and its market share when the two products are close substitutes. This reverses the effects of a competition shock in the absence of promotion. The rationale is that the more substitutable the two goods are, the more aggressively $A$ and $B$ compete prior to generic entry, in phase 1 . This translates into initially lower prices and higher promotion. In that situation, generic entry has a comparatively small impact on prices: the reduction in promotion dominates. High levels of differentiation have the opposite effect: prices are initially high and promotion low. Then, generic entry primarily affects prices: both $A$ 's and $B$ 's prices drop.

Second, $B$ benefits from $A$ 's loss of exclusivity when the market is large and profitable. The reason is that these are the markets in which firms initially invest the most in promotion and detailing. Then again, profit erosion on the $A$-segment after generic entry triggers a large drop in promotion intensity for $A$, which eases competitive pressure on $B$. Hence, the prediction of the model is that generic competition significantly curtails $B$ 's market share only in small and comparatively less profitable markets.

Third, we can compare the market outcome in each of the first and second phase with the market outcomes that would result from perfectly competitive market conditions (third phase). Compared to that benchmark, we find that the market allocation is always worsened by asymmetric competition: the market share of $A$ only increases when it is already too high in the first place, and it only decreases (to the benefit of $B$ ) when it is already too low (we 
briefly discuss welfare in the concluding section).

Bringing these results to the data, we find that they are more than a theoretical construct: using a data trove tracking prices, promotion, and quantities sold in the USA during the period 1994-2003, we show that competition by generics in the multi-billion-dollar pharmaceutical market often fails to put effective pressure on the drugs that remain protected by a patent. As detailed in Section 2, despite price drops as high as $45 \%$ for the drug experiencing generic entry, the average effect is to boost the market share of competing molecules. The volume market share of the molecule that is now cheaper-the originator drug plus its chemically equivalent generic version - drops by $31 \%$ in the pharmacy channel and by $26 \%$ for drugs sold in hospitals.

Instances of generic entry are also an ideal testing ground for technical reasons. First, generic entry typically results from an exogenous cause: the loss of patent protection. It has a set date, some 20 years after the patent was introduced. ${ }^{4}$ It also produces a competition shock that is quite different from the entry of new competing products. Such a clear dichotomy between the launch of new products and the loss of market power for a single product would be difficult to observe in other markets. Second, agency issues between patients, physicians, and insurances likely increase the sensitivity of demand to promotion relative to prices, which magnifies the effects we are after.

Our sample covers all prescription sales in the U.S. between 1994Q1 and 2003Q4 (40 quarters). From that dataset, we extract all the therapeutic classes ("ATC3 markets") for which data on prices, quantities, and promotional efforts are available. We then cross these data with that of the FDA to identify episodes of generic entry (see Section 4). This leaves us with 95 episodes of generic entry scattered over 53 different ATC3 markets.

After controlling for other sources of heterogeneity, we find that, on average, generic entry alone causes a $15 \%$ increase in market share for molecules that remain on patent. The effect is smaller in the hospital channel: in part because of effective procurement processes, hospitals display higher price elasticity. In line with theoretical predictions, this reinforces the

\footnotetext{
${ }^{4}$ Such a long delay also ensures that the firm's entry decision and choice of a "horizontal location" (Hotelling, 1929) or of a "vertical differentiation" (Shaked and Sutton, 1982) are both exogenous to the characteristics of competition and residual market size at the time of LoE. This produces substantial exogenous variation across episodes of generic entry, which we exploit in our empirical analysis.
} 
effect of price competition-by about 4 percentage points. We also propose a novel measure of product differentiation for the pharmaceutical industry based on the number of modes of action within a therapeutic class. Again in line with predictions, differentiation knocks another 4 percentage points off the market share gain of the competitors. Last, the market share gain is further reduced by 8 percentage points in "small" markets. All these results are more pronounced when the molecule experiencing the LoE was a blockbuster. Finally, we explore the connection between our findings and evergreening (the presence of a secondgeneration product by the same originator). In particular, in Section 6.1 we show that the gains in market share of on-patent drugs is more pronounced when the originator company that experiences LoE also owns patent rights on another drug in the same therapeutic market. In other words, evergreening turns out to be a strategic complement to the promotion effects identified by our model.

Related literature. Our paper is at the intersection of several literature strands, including industrial organization, advertising, and health economics. With regard to our empirical application, the existing literature on competitive interactions in the pharmaceutical industry has produced a complex, and sometimes contradictory, picture. One group of papers analyzes inter-brand competition when drugs are still patent-protected (see, for instance, Brekke and Kuhn (2006) for a theoretical model and Dave and Safer (2012) for empirics). de Frutos, Ornaghi and Siotis (2013) analyze inter-brand competition when the proportion of brand-loyal consumers is endogenously determined by promotional effort.

Another strand focuses on intra-molecular competition following loss of exclusivity - i.e., when a generic bio-equivalent drug can legally come to market (e.g. Scott Morton (2000)). ${ }^{5}$ It was in that context that the "generic entry paradox" has been unearthed (the paradox being that the price of the originator drug often goes up following the launch of a competing chemically equivalent generic). This empirical finding has been thoroughly documented (see a.o. Caves et al. (1991); Regan (2008); Vandoros and Kanavos (2013)).

The few papers that attempted to simultaneously analyze pre- and post-LoE competition have produced a mixed picture. For instance, Stern (1996) provides evidence of intense inter-

\footnotetext{
${ }^{5}$ See Grabowski and Kyle (2007) for a description of generic entry in the U.S. in the period 1995-2005, and Berndt and Dubois (2016) for a comparison of generic penetration across OECD countries for the period 2004-2010.
} 
molecular competition, whereas Ellison et al. (1997) reports strong intra-molecular rivalry between the originator and the generic version of the drug, as well as weak (or insignificant) inter-molecular competition.

A related literature focuses on the relative importance of the persuasive and informative roles of promotional effort (Ching and Ishihara (2012)) and on whether detailing and directto-consumer advertising have a market expansion effect (Ching et al. (2016); Iizuka (2004, 2005); Fischer and Albers (2010)). Mizik and Jacobson (2004) analyze the effectiveness of promotional effort by estimating the long-run effect of detailing and sampling on prescriptions for three drugs. Manchanda, Rossi and Chintagunta (2004) assess whether, from a business perspective, detailing is misallocated across individual physicians. Narayanan and Manchanda (2009) show that the persuasive effect dominates at the end of a molecule's exclusivity period.

Huckfeldt and Knittel (2011) show that evergreening strategies (the launch of a secondgeneration product by the same originator) helps explain instances of volume market share drop of the previous generation molecule, despite being sold at a fraction of the original price. Lakdawalla and Philipson (2012) share our motivation (volume sales drop following LoE) and exploit a similar sample. The main difference lies in the fact that we explicitly model competition, and derive testable implications that help explain the heterogeneity in market reactions they identify.

The remainder of the paper is organized as follows. Section 2 presents some facts central to our research question. Section 3 presents the model and derives testable implications. Section 4 describes the data, while Section 5 presents the empirical results. Section 6 reports robustness and sensitivity checks. Section 7 concludes by discussing how the presence of nonprice instruments can lead to mismatch between consumers and goods when competition is asymmetric. 


\section{Generic competition: some empirical regularities}

\subsection{Price, patents, and quantities}

Here, we detail our claim that, while generic entry produces a dramatic change in competitive conditions, its effects substantially deviate from the predictions of elementary models of industrial organization.

The expected effect is as follows: generics being typically sold at a fraction of the price of the original brand, they exert strong competitive pressure on the originator: Grabowski et al. (2014) show that, for branded drugs facing generic entry in 2011-2012, brands retained on average only $16 \%$ of the molecule market after one year. Figure 1 provides another perspective on these evolutions. Lumping together the original brand and its generic equivalents, it depicts the evolution of the mean and median price and quantity for the 95 molecules that experienced generic entry in our dataset (U.S. data for the period 1994Q1-2003Q4). Time is expressed in quarters, and we denote as "date 0" the quarter in which molecules lose exclusivity. We normalize to 1 values at quarter -12 .

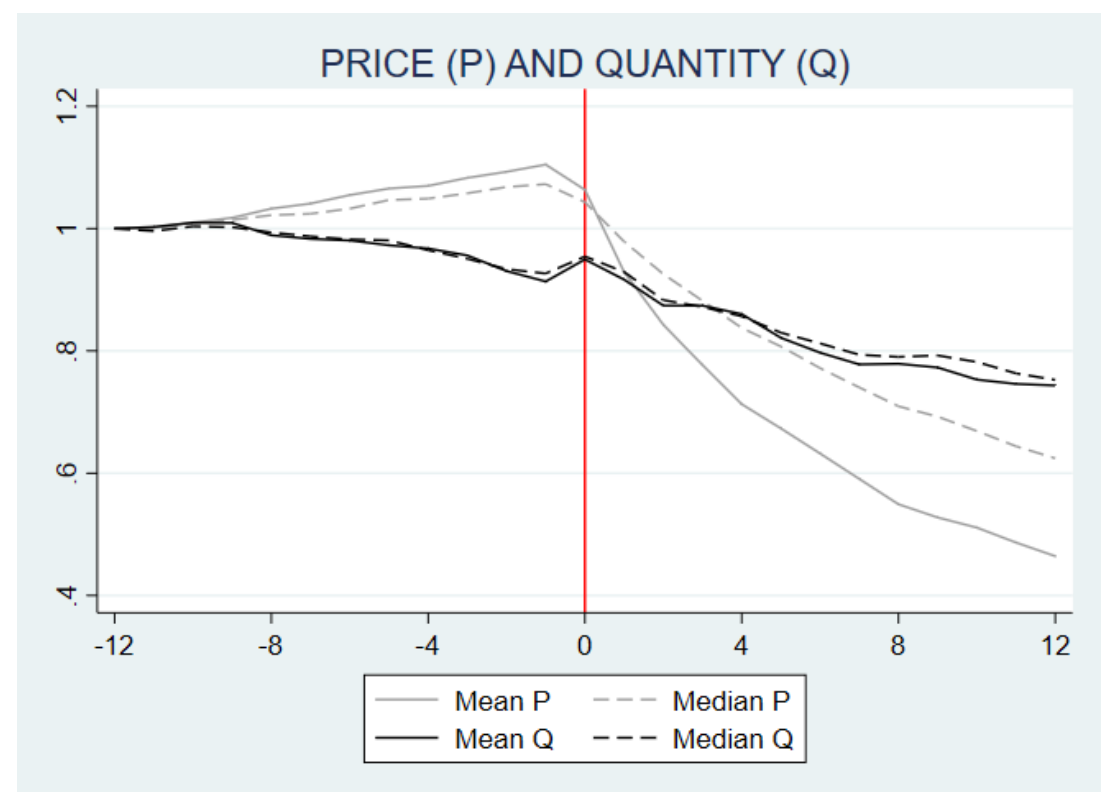

Figure 1: Price and Quantity around generic entry. Quarter-by-quarter evolution of the mean and median Price and Quantity for the 95 molecules that experienced generic entry in our dataset (U.S. data for the period 1994-2003; quarter 0 identifies generic entry). 
What stands out is that, within a year of the Loss of Exclusivity (LoE), mean (respectively, median) prices drop by about 30\% (20\%). Within three years, the drop reaches about $50 \%$ $(40 \%){ }^{6}$ In spite of this, sales in volume drop, on average, by more than $25 \%$ within three years of patent expiry. ${ }^{7}$ As our econometric analysis will show, this means that generic entry mainly benefits competing molecules. Put differently, few new patients are directed to the cheap genericized molecule, and a number of existing patients switch to competing molecules just when their treatment becomes cheaper. Neither the rationales for the generic entry paradox nor third party payer reimbursement rules can explain why cross-price elasticities suddenly seem to take the "wrong sign".

\subsection{Loss of exclusivity and promotion intensity}

Turning to promotion, Figure 2 shows that LoE also triggers a major drop in the firms' promotional effort (we will use the terms detailing, promotion and advertising as synonymous). Using data from IMS-Health, we measure the firms' drug-specific spending on personalized visits to general practitioners and hospital specialists, free samples dispensed to physicians, and advertising in professional journals. All these instruments affect the physicians' incentives to prescribe one drug rather than another. The data reveal that promotion falls continuously over the 12-quarter period before patent expiration, with a sharp acceleration around the time of LoE. At time 0, promotion effort already dropped by $50 \%$. Four quarters later, the median drop is close to $95 \%$. At 12 quarters after LoE, median spending is zero. ${ }^{8}$

The fact that price and promotion dynamics may have offsetting effects was already

\footnotetext{
${ }^{6}$ Although the average price of the molecule (displayed) falls following generic entry, this is not always the case for the price of the branded drug (not separately depicted in Figure 1). Sometimes, the latter remains constant or even increases; this is the so-called generic entry paradox (for empirical evidence, see Regan (2008) for the U.S. and Vandoros and Kanavos (2013) for the EU). This behavior is usually attributed to the fact that a subset of patients insist on purchasing the brand, even at a higher price. This allows branded producers to keep extracting rents on a (shrinking) subset of patients.

${ }^{7}$ The only significant exception pertains to the quarter of when generics enter the fray. Lakdawalla and Philipson (2012)'s monthly data show that $60 \%$ of the molecules gain volume in the first two months surrounding generic entry (see their Figures 1 and 7). However, these gains are reversed by month 4 . Stock adjustments may be one of the drivers of this increase.

${ }^{8}$ The average lies above the median because some molecules continue to be promoted. For instance, high levels of promotions are observed for Prozac (fluoxetine) because Eli Lilly \& Co. introduced weekly delayed release capsules of the drug just before LoE in an attempt to stem the post-patent decrease in sales of their daily dosage. Similarly, we observe positive spending for Zantac (ranitidine) and Tagamet (cimetidine), probably because some of their lower-dosage tablets are available over-the-counter (no prescription required).
} 


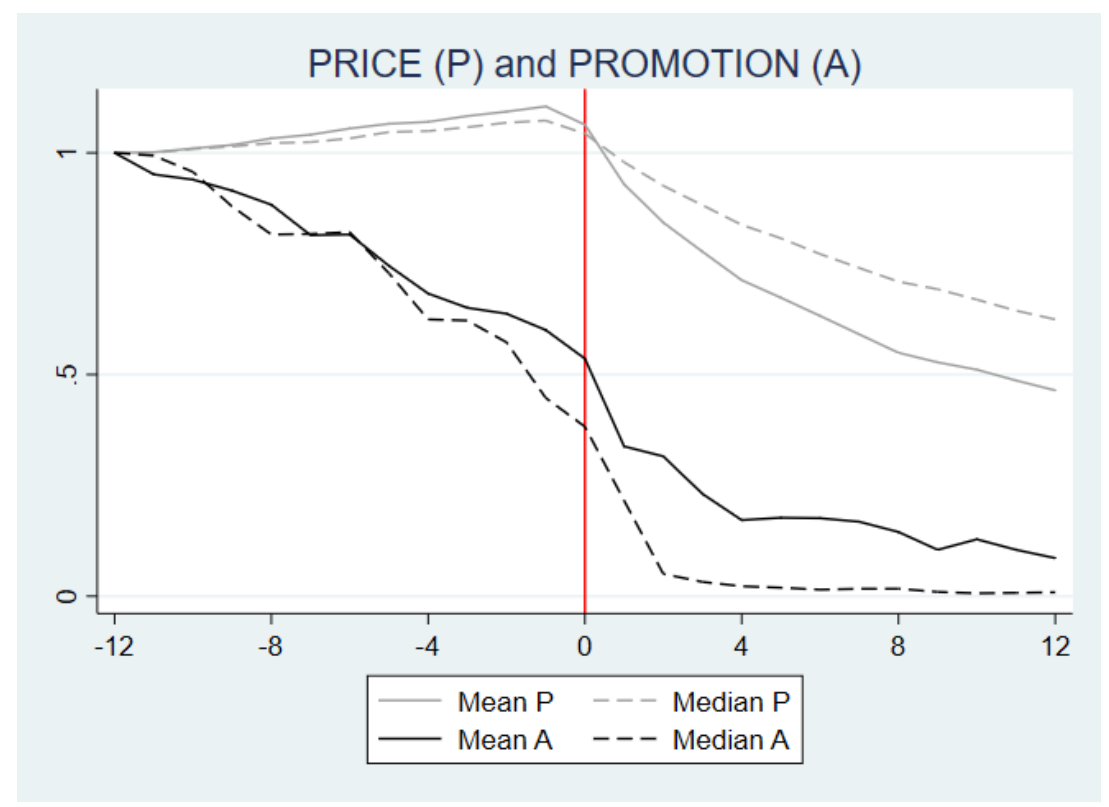

Figure 2: Price and Promotion around generic entry

emphasized by Caves, Whinston and Hurwitz (1991). However, they did not explore the matter further, either theoretically or empirically. Subsequent empirical research confirmed that sales may increase or decrease: Berndt et al. (2003), Lakdawalla et al. (2007), and Lakdawalla and Philipson (2012, Figures 7 and 9) find that the volume of sales does not increase after LoE, and that firms cut down on promotion effort. Aitken et al. $(2009,2013)$ report increased sales. Duflos and Lichtenberg $(2012$, p95) find that "the net effect of patent expiration on drug utilization is zero".

However, the literature falls short of explaining when and why one or the other outcome should materialize, or even if these apparently haphazard evolutions really are the result of the tension between prices and promotion. Our purpose is to investigate that very question.

\subsection{Generic Entry vs. Evergreening?}

Before moving to the formal analysis of that question, we briefly discuss evergreening strategies, a candidate explanation for the phenomena described in the previous section. Evergreening consists in the launch of new formulations or second-generation versions of a drug, leading to "product hopping" by patients (see Huckfeldt and Knittel (2011) for a detailed 
analysis). The logic is for the firm losing exclusivity on some drug $A$ to launch a "new" drug $A^{\prime}$ and stimulate patients' migration before LoE. When successful, this shrinks the market share of the original product, leaving generic entrants little to compete for. ${ }^{9}$

While we acknowledge that this can be an important driver of the transfer to "new" molecules, we show in Section 6.1 that evergreening is not a substitute to the effect we identify. First, because only a fraction of the LoE episodes in our dataset could be associated with evergreening. Our empirical results are robust to the exclusion of these episodes. Second, an effective promotion strategy is necessary to organize the patient migration towards the second-generation product. The fact that the firm losing exclusivity and the firm proposing a replacement drug are one and the same should only make promotion more effective. This is exactly what we report in Section 6.1.

\section{The model}

To analyze the effects of generics entry, we build on a textbook model of differentiated Bertrand competition with advertising. That is, (1) initially, two firms sell differentiated drugs and compete through price and promotion. In contrast with the standard textbook approach, we consider (2) a competition shock that is highly asymmetric: a generic is a perfect substitute for one molecule in an otherwise horizontally differentiated industry. (3) In the spirit of Inderst and Ottaviani (2012), consumer decisions are mediated through intermediaries who can be persuaded to modify their purchasing recommendations. In our framework, however, this is only relevant for the normative analysis: realized consumption decisions may differ from those that would maximize the utility of the final consumer.

While our textbook model overlooks interesting complexities of pharmaceutical markets, it clarifies that our results are exclusively driven by the interaction between price and promotion

\footnotetext{
${ }^{9}$ The EU Commission's Sector Inquiry (2009) gathered evidence on the tactics deployed to support evergreening. One EU national authority reported that: "In fact, there are special strategies linked to patents, which can constitute barriers to entry for generics. A quick legal research allowed [us] to supply a few examples: Modification of composition of the pharmaceutical specialty; Extension of therapeutic indication [...]; Launching of an enantiomer; and registering a patent as regards a new formulation, which is presented as more efficient." (Sector Inquiry -SI-, p.358, \#1019). A wholesaler noted that "[...] originator companies have attempted to reduce the impact of pending generic competition by introducing apparent last minute improvements to products, or by changing the galenic form of their molecule." (SI, p. 358, \#2021).
} 
strategy. We further discuss our assumptions at the end of this section.

Two firms, $A$ and $B$, initially compete both in prices $p$ and in "advertising," $a$ - or any other fixed cost that stimulates demand. We then study the effects of the entry of one or more generic firms, $G$, that produce a perfect substitute for firm $A$ 's drug - note that we are not contemplating evergreening strategies, nor the launch of a "branded" or "authorized" generic. Intuitively, substitutability implies that $A$ 's advertising effort produces a positive spillover on $G$. However, competition between $A$ and $G$ causes both the price and advertising effort of $A$ to drop. Our central question is: what happens to the demand for $B$ ?

Formally, we derive the firms' promotion and pricing strategy given the quality $\theta_{J}$ of their molecule, the heterogeneity of treatment responses across patients, $e,{ }^{10}$ and the agents' sensitivity to price, $\delta .^{11}$ In the spirit of Shaked and Sutton (1982), consider a patient $i$ who goes to her physician with a condition that requires treatment. The intrinsic utility of the Patient-Physician-Payer triplet ("P3" henceforth) ${ }^{12} i$ 's from using treatment $A$ or $B$ is, respectively (we introduce advertising below):

$$
\begin{aligned}
& U_{A}^{i}=\theta_{A}-\delta p_{A}+\varepsilon^{i} \\
& U_{B}^{i}=\theta_{B}-\delta p_{B}-\varepsilon^{i}
\end{aligned}
$$

where $p_{J}$ is the price of molecule $J \in\{A, B\} ; \varepsilon^{i} \sim \mathrm{U}\left[-\frac{e}{2}, \frac{e}{2}\right]$ is the relative efficiency of drug $A$ as opposed to $B$ to treat patient $i$ 's condition; and $\mathrm{U}\left[\right.$.] denotes the uniform distribution. ${ }^{13} \mathrm{~A}$ larger value of $e$ implies that patients are more heterogeneous in their response to treatments, and hence that the two molecules are more distant substitutes. The parameter $\delta$ accounts for their price sensitivity.

\footnotetext{
10 These parameters directly relate to vertical and horizontal product differentiation in classical industrial organization analyses. However, product differentiation is not a choice variable in our model.

${ }^{11}$ This model specification fits the industry's description provided by Berndt (2002): "Within many therapeutic classes of drugs, a number of possible substitute medications exist, and in such cases, the market structure is more appropriately depicted by the differentiated product oligopoly framework. In such a setting, it is useful to envisage the optimal profit maximizing price as equaling marginal cost plus a positive margin, where the margin depends on benefits and attributes (including prices) the firm's own drug relative to other drugs in the therapeutic class, on attributes of non-drug therapies, patient heterogeneity and other demand-side considerations."

${ }^{12}$ The "payer" can be a Third Party Payer (TPP), patient out-of-pocket expenditure, or a combination.

${ }^{13}$ Focusing on a single random variable $\varepsilon$ that can be either positive or negative implicitly eliminates patients with negative valuations of the two molecules, who have no reason to consume either of the two drugs. Thus, issues of aggregate under- or over-prescription are beyond what this model can capture.
} 
Horizontal differentiation implies that patients with a sufficiently good fit with drug $A$ (i.e., with $\varepsilon^{i}$ sufficiently positive) buy treatment $A$, and the others buy $\operatorname{drug} B .{ }^{14}$ Letting $\mu$ denote market size (or the number of afflicted patients), we identify the patient $i$ who is indifferent between $A$ and $B$ to determine quantities in the absence of detailing:

$$
\begin{aligned}
Q_{A} & =\left(1-F\left(\frac{\Delta \theta_{B}-\delta \Delta p_{B}}{2}\right)\right) \times \mu \\
Q_{B} & =F\left(\frac{\Delta \theta_{B}-\delta \Delta p_{B}}{2}\right) \times \mu,
\end{aligned}
$$

where $F$ represents the CDF of $\varepsilon^{i}, \Delta \theta_{B} \equiv \theta_{B}-\theta_{A}$, and $\Delta p_{B} \equiv p_{B}-p_{A}$. We associate drug $A$ with the oldest molecule, while $B$ is more recent: firm $A$ loses exclusivity before $B$. For the sake of the argument, we focus on the case $\Delta \theta_{B} \geq 0$, since more recent drugs are expected to be more effective than older ones. However, all the results extend to the complementary case of $\Delta \theta_{B}<0$. Thus, when they cannot promote their drugs (superscript $N D$ for the "No Detailing" case), the two firms' respective profits are:

$$
\begin{aligned}
& \pi_{A}^{N D}=p_{A} \times\left[\frac{1}{2}-\frac{\Delta \theta_{B}-\delta \Delta p_{B}}{2 e}\right] \times \mu, \\
& \pi_{B}^{N D}=p_{B} \times\left[\frac{1}{2}+\frac{\Delta \theta_{B}-\delta \Delta p_{B}}{2 e}\right] \times \mu,
\end{aligned}
$$

where the terms between brackets are, respectively, the market shares of $A$ and $B$ when we substitute for the value of $F$ under the uniform distribution. ${ }^{15}$

\footnotetext{
${ }^{14}$ This model specification assumes that all the patients who require a treatment receive one (full market coverage). This requires that the quality $\theta_{J}$ of both molecules is sufficiently high relative to the equilibrium prices-formally, $\theta_{A}+\theta_{B}>2 e$ (see Appendix 1). To capture incomplete coverage, we used another model specification that adds the distribution of willingness to pay $\omega^{i}$ into the utility function:

$$
U_{A}^{i}=\theta_{A}-\delta p_{A}+\varepsilon^{i}+\omega^{i}, \text { and } U_{B}^{i}=\theta_{B}-\delta p_{B}-\varepsilon^{i}+\omega^{i} .
$$

Solving for the demand for, say, $A$, then shows that $Q_{A}$ in equation (3) must be multiplied by: $\left(1-F_{\omega}\left(\delta p_{A}-\theta_{A}-\frac{\Delta \theta_{B}-\delta \Delta p_{B}+e}{4}\right)\right)$ in the simple case where the distribution of $\omega$ is also uniform. This term captures the market contraction/expansion effects of higher/lower prices. This does not affect the substance of our analysis of market shares. Since we do not have a strong case as to whether there is initially under- or over-provision of drugs, we decided not to incorporate these effects in the model: they make the analysis a lot less tractable, for little benefit.

${ }^{15}$ Formally:

$$
F(\varepsilon)=\left\{\begin{array}{l}
0, \forall \varepsilon<-e / 2 \\
\frac{\varepsilon+e / 2}{e}=\frac{1}{2}+\frac{\varepsilon}{e}, \forall \varepsilon \in[-e / 2 ; e / 2] \\
1, \forall \varepsilon>e / 2 .
\end{array}\right.
$$

and the $\operatorname{PDF}$ is $f(\varepsilon)=1 / e, \forall \varepsilon \in[-e / 2 ; e / 2]$.
} 
Generic Entry in the absence of promotion. The above setup describes a duopoly market: each firm's patent gives it exclusivity for the sale of its molecule. Now, we turn to the effects of $A$ losing that exclusivity (LoE), while firm $B$ retains its patent protection and monopoly power

The first case we study is the one in which there is no detailing. In the absence of detailing, an equilibrium is characterized by a pair of prices in which firms maximize profits in $(3)-(4)$. Loss of exclusivity implies that chemically equivalent generics can compete directly for $A$ consumers. Empirical evidence (see a.o. Grabowski et al., 2014) shows that generics are very effective competitors to the originator drug, and that competition among generics can dramatically compress profit margins. Here, we let generic entry drive the

price of $A$ to marginal costs, which we normalize to zero without loss of generality (but see discussion below).

The post-generic-entry equilibrium is then characterized by the price that maximizes $B$ 's profits when $p_{A}=0$. Unsurprisingly, the results in Appendix 1 show that generics competition against $A$ can only drive down the price and market share of drug $B$. We also find that, in an interior equilibrium, price sensitivity determines the magnitude of the price reduction, but does not influence market shares.

Competition in the presence of promotion. As discussed in the introduction and in Section 2.2, the pharmaceutical industry stands out for its high promotional intensity. Through their detailing and sampling activities, pharmaceutical companies devote substantial resources to inform physicians and provide them with a number of perquisites, sometimes contingent on their prescription behavior. This non-price competition component is also affected by generic entry: price competition with generics brings detailing down to 0 .

We assume that promotion is persuasive: it stimulates prescriptions without affecting the patient's intrinsic utility (1) - (2) nor bringing fresh information to doctors. As we discuss below, this reflects the situation at the end of a molecule's life cycle.

Formally, when firm $J$ spends $C\left(a_{J}\right) \equiv a_{J}^{2} / 2$ on promotion, it produces an autonomous increase in the demand for $\operatorname{drug} J$ from $\theta_{J}$ to $\theta_{J}^{\prime}=\theta_{J}+a_{J}$. Given an action profile 
$\left\{a_{A}, a_{B}, p_{A}, p_{B}\right\}$, the resulting demands are then:

$$
\begin{aligned}
Q_{A}^{D} & =\left(1-F\left(\frac{\Delta \theta_{B}+\Delta a_{B}-\delta \Delta p_{B}}{2}\right)\right) \times \mu, \\
Q_{B}^{D} & =F\left(\frac{\Delta \theta_{B}+\Delta a_{B}-\delta \Delta p_{B}}{2}\right) \times \mu,
\end{aligned}
$$

where superscript $D$ denotes Detailing and $\Delta a_{B} \equiv a_{B}-a_{A}$. The firms' profits become:

$$
\begin{aligned}
& \pi_{A}^{D}=p_{A} \times\left[\frac{1}{2}-\frac{\Delta \theta_{B}+\Delta a_{B}-\delta\left(p_{B}-p_{A}\right)}{2 e}\right] \times \mu-\frac{a_{A}^{2}}{2}, \\
& \pi_{B}^{D}=p_{B} \times\left[\frac{1}{2}+\frac{\Delta \theta_{B}+\Delta a_{B}-\delta\left(p_{B}-p_{A}\right)}{2 e}\right] \times \mu-\frac{a_{B}^{2}}{2} .
\end{aligned}
$$

Discussion of the main assumptions. We made three important assumptions. First, patients do not observe the relative importance of price and promotion in determining their physician's prescription decision. The fact that both prices and promotion may influence prescription behavior is well grounded in facts, and the purpose of the theoretical model by Inderst and Ottaviani (2012), who study how commissions and kickbacks -and the consumers' information about them- influences eventual market outcomes and welfare. Iizuaka (2012) provides evidence that physicians respond to economic incentives in their prescription decisions. The association between payments to physicians and their prescription behavior can also be assessed on the basis of publicly available data (Grochowski, Jones, and Ornstein (2016), Greenway and Ross (2017), and JAMA (2017)). Second, we treat promotion as persuasive. In the context of our paper, the underlying assumption is that the informative component is more relevant earlier in a molecule's life cycle, while the persuasive dimension dominates around LoE, which is the time window we focus on. This is supported by Hurwitz and Caves (1988) and Rizzo (1999), who provide extensive evidence pertaining to the persuasive nature of pharmaceutical detailing, and by Narayanan and Manchada (2009, p. 437), who report that the informative component becomes dominated by persuasive effects as time passes.

Third, we assume that generic entry switches the competitive environment for a particular molecule $(A)$ from a pure monopoly to perfect competition. This oversimplifies reality, and would be inappropriate if our focus was on intra-molecular competition. That aspect of 
generic competition has been studied, and found to also produce its own interesting, sometimes paradoxical, effects (see Section 2). However, even if one could generalize the model, this simplified setup already captures key stylized facts of interest (see footnote 17, page 15). More importantly, since our objective is to focus on the effects of generic entry on intermolecular competition, we abstract from the details of intra-molecular competition. This singles out our contribution.

\subsection{Equilibrium before generic entry}

Before generic entry, each P3 has only a choice between two branded molecules. Each firm chooses its price and promotion intensity to maximize its profits. Taking first-order conditions yields the implicit solutions:

$$
\begin{aligned}
p_{J}^{D} & =\frac{2 e}{\delta} \frac{Q_{J}}{\mu}, \\
a_{J}^{D} & =\frac{Q_{J}}{\delta} .
\end{aligned}
$$

This, in turn, implies (mathematical developments are in Appendix 3):

Result 1 The price $p_{J}^{D}$ is increasing in the molecule's market share $\left(Q_{J} / \mu\right)$, and promotion intensity $a_{J}$ is increasing in quantity $Q_{J}$, and hence in market size, $\mu$. Both are decreasing in the P3's price sensitivity $\delta .^{16}$ Moreover, prices (but not promotion) are increasing with the degree of "horizontal differentiation" $e$.

In Appendix 2, we test this result on our data. We find that prices, promotion and market shares co-move positively, as Result 1 predicts. Importantly, however, this requires proper instrumentation to control for the confounding influence of the demand side of the ledger that affects the raw correlation between prices and market shares. We interpret this result as a confirmation that our theoretical model, even if very simple, does capture important features of the nature of competition between large pharmaceutical companies.

\footnotetext{
${ }^{16}$ This result is in line with, e.g., de Frutos et al. (2013) or Brekke and Khun (2006), who write that "detailing, DTCA and price (if not regulated) are complementary strategies for the firms. Thus, allowing DTCA induces more detailing and higher prices." Similarly, Grossman and Shapiro (1984) find that more competitive markets reduce both prices and advertising in a model in which the purpose of advertising is to inform consumers of a product's existence.
} 
In Appendix 3, we analytically show that, when the two molecules are closer substitutes (smaller $e$ ), the market share of the superior drug decreases towards $50 \%$, because firm $B$ invests less in promotion, whereas $A$ invests more. Conversely, a larger market size $(\mu)$ magnifies the gap between $B$ and $A$ : with higher potential profits, $B$ invests in promotion more aggressively and, hence, increases its market share.

\subsection{The effects of generic entry}

After LoE, generic entry drives the price of molecule $A$ to $p_{A}=M C=0$, and the dissipation of profits produces a drop in detailing: $a_{A}=0 .{ }^{17}$ As a consequence, firm $B$ 's post-entry profit function becomes:

$$
\pi_{B}^{G}=p_{B} \times\left[\frac{1}{2}+\frac{\Delta \theta_{B}+a_{B}-\delta p_{B}}{2 e}\right] \times \mu-\frac{a_{B}^{2}}{2} .
$$

Where superscript $G$ stands for Generics: firm $B$, which still benefits from market power, faces stiffer price competition but looser non-price competition from molecule $A$. We find:

Proposition 1 For $Q_{A}^{D}, Q_{A}^{G}>0$, the loss of exclusivity on molecule $A$ allows $B$ to increase its market share, promotional effort, and price iff $2 \delta e<\mu$.

Proof. From Propositions 2 and 3 in Appendix 2, it is relatively straightforward to show that $Q_{B}^{G}-$ $Q_{B}^{D}, a_{B}^{G}-a_{B}^{D}$, and $p_{B}^{G}-p_{B}^{D}$ are all a multiple of $(2 \delta e-\mu)\left(\delta\left(\Delta \theta_{B}-3 e\right)+\mu\right)$, where the second factor is negative whenever $Q_{A}^{D}$ is positive.

It is striking that it is precisely when $A$ and $B$ are closer substitutes (e small enough) that asymmetric price competition by the generic versions of $A$ ends up benefiting $B$. Conversely, only if the two molecules are sufficiently distant substitutes or if market size $\mu$ is small, will price competition have the (a priori expected) effect of boosting the sales of molecule $A$.

The rationale for this result stems directly from firm $A$ 's pre-LoE behavior: Proposition 2 in Appendix 3 shows that, in the pre-generic entry equilibrium, $p_{J}^{*} / a_{J}^{*}=e / \mu$. This follows quite naturally from the Dorfman-Steiner (1954) equilibrium conditions. Here, they imply that when market size is large and/or the two firms sell close substitutes, $A$ invests

\footnotetext{
${ }^{17}$ Note that in our data, generics' producers do not promote their drugs to physicians and hardly advertise in the media.
} 
comparatively more in promotion and/or keeps its price low. As a consequence, generic entry substantially loosens non-price competition $\left(a_{A}\right.$ drops from that comparatively high level down to 0 ) and have a comparatively smaller effect on price ( $p_{A}$ dropping from that comparatively low level to 0 ).

Conversely, when market size is small and $A$ and $B$ are distant substitutes, competition is initially lax (i.e., prices are comparatively higher and promotion lower). In that case, generic entry produces a stronger price drop in comparison to promotion, which dents the demand for $B$, and forces the latter to react by adopting a more aggressive pricing strategy. Proposition 1 allows us to derive the following:

Testable implication 1 Generic entry should produce lower gains in market share for $B$ in markets where price sensitivity $\delta$ is higher.

Testable implication 2 Generic entry should produce larger gains in market share for $B$ in markets where horizontal differentiation e is lower.

Testable implication 3 Generic entry should produce larger gains in market share for B in larger markets.

The equilibrium outcome whereby close substitutes are most heavily promoted in large markets fits nicely with one observation. Based on Donohue et al. (2007), who identify the products most heavily advertised through Direct to Consumer Advertising (DTCA), Kenkel and Mathios (2012) note that a "striking feature of the US Top 20 list was the number of competing products for the same medical condition." In New Zealand, the other country where DTCA is allowed, the composition of the Top 20 list was different: only four drugs appeared on both countries' lists. This is due to reimbursement rules: in New Zealand, only one product per therapeutic class is subsidized (hence, it makes little sense to advertise the non-subsidized product). There is, however, one condition-erectile dysfunction-for which New Zealand's Pharmaceutical Management Agency (Pharmac) does not subsidize any drug. This is also the exception in the respective Top 20 lists: contrary to the other product categories, two close substitutes, Viagra and Cialis, are heavily advertised in both countries. 
In Appendix 4, we extend the model to study allocative efficiency and patient surplus (when the patient does not value promotion directly). First, we find that asymmetric generic entry never improves allocative efficiency: the market share of $B$ increases when it is already too large compared to the first best, and it decreases when it is already too low prior to LoE. In other words, the asymmetric shock always distorts the market allocation further away from the first best. Banning promotion overall would not solve this issue: the results are identical in the absence of promotion. The reason is that the highest quality drug tends to be sold at a higher markup, and generic entry reduces the price of only one molecule, generating inefficient, lopsided competition.

The second result in Appendix 4 aims at evaluating when generic entry increases or decreases consumer (patient) surplus. Based on the logic of Inderst and Ottaviani (2012), we acknowledge that promotion influences the behavior of the intermediary (the physician) whereas consumer surplus requires using the utility functions (1) and (2). This implies that promotion does not enter directly in the definition of consumer surplus.

We find that the effect of generic entry on consumer surplus varies on a case-by-case basis: even though allocative efficiency worsens, patients benefit from the lower prices of $A$ and, in some cases, of $B$. We identify that a drop in $Q_{B}$ is a sufficient condition for patients' utility to increase. Conversely, for $\Delta \theta_{B}=0$, consumer surplus decreases only if the market share of $B$ increases strongly. We return to these points in the conclusion, once we have assessed actual market responses in the data.

\section{The Data}

\section{Markets, sub-markets, and product differentiation}

We started from a dataset covering quarterly dollar revenues and physical quantities for hundreds of branded and generic prescription drugs sold in the U.S. in virtually all therapeutic areas over the 40-quarter period 1994q1 to 2003q4. These have been obtained from the proprietary database IMS-Health, one of the most important medical-information providers (IMS-MIDAS). All the drugs in IMS-Health are classified according to the Anatomical Therapeutic Chemical (ATC) classification system. The ATC3 level should correspond to a market: 


\begin{tabular}{cc||cc}
\hline \hline \multicolumn{2}{c||}{ Market Descriptive Statistics } & \multicolumn{2}{c}{ Molecule Descriptive Statistics } \\
\hline \# ATC3 & 53 & \# molecules & 227 \\
\# ATC4 & 75 & \# LoE & 95 \\
\hline \hline \#Gen. entries & \#Markets in sample & \#ATC4 in ATC3 & \%age obs'ns \\
\hline 0 & 8 & 1 & $56.8 \%$ \\
1 & 22 & 2 & $20.2 \%$ \\
2 & 8 & 4 & $13.3 \%$ \\
3 & 8 & 5 & $4.3 \%$ \\
4 & 3 & 6 & $1.7 \%$ \\
5 & 3 & & \\
\hline Total: & 1 & Total: & $100 \%$ \\
\hline \hline
\end{tabular}

Table 1. Therapeutical Markets, Molecules and Generic Entry

it groups the drugs that target a given condition.

In IMS data, generics have the name of the active ingredient. ${ }^{18}$ We thus compiled an initial list of ATC3 markets with generic entry by selecting the markets where some of the drug names are the same as the molecule (e.g. Fluoxetine is the active ingredient of Prozac, as well as the name of its generic competitors). We double-checked and completed this list with information about LoEs from the FDA and other sources. We then contacted IMS-Health to purchase drug-level information on promotion expenditure for the selected therapeutic markets, as well as other important ATC3 markets in terms of sales. Information on promotion was not available for some markets. In spite of this, the final sample we assembled for the empirical analysis still includes 53 different ATC3 therapeutic areas, each representing a different "market".

Table 1 provides descriptive statistics for these markets and associated molecules. Our final sample includes 227 drugs initially covered by patent protection, 95 of which lost patent protection between 1994 and 2003. Forty-five of the 53 selected markets experienced the entry of at least one new generic molecule during the observed time window, with one market experiencing six LoEs.

The 53 ATC3 therapeutic areas are further subdivided into ATC4 sub-classes which cor-

\footnotetext{
${ }^{18}$ This is not the case for branded generics, which are sold with a trade name different from the name of the molecule. IMS Health began tracking and reporting on branded generics in 2002, meaning that only three instances are present in our dataset. In the empirical analysis, we treat them as plain vanilla generics.
} 
respond to different modes of action to treat the same pathology. The complete list of ATC3 markets and ATC4 sub-classes we use in the empirical analysis can be found in Appendix 5. The list includes the most important therapeutic areas, such as lipid regulators, antidepressants, anti-ulcer drugs and hypertension drugs.

For illustrative purposes, Table 2 reports the list of (plain) lipid regulators for the main two ATC4 subclasses of the ATC3 anti-cholesterol market: statins and bile acid sequestrants. ${ }^{19}$ The former is composed of six competing molecules, while the latter has four. Thus, in total, there are up to ten different prescription possibilities for a patient with excess cholesterol. The last column identifies either the quarter in which the drug lost its patent protection (4th quarter of 2001 in the case of Mevacor, for instance) or the date on which the company decided to withdraw the molecule from the market (lethal secondary effects triggered the early withdrawal of Lipobay in 2001).

We use of the structure of these ATC3 markets and ATC4 subclasses to develop a measure of the degree of horizontal differentiation $(e)$. Since each ATC4 therapeutic subclass corresponds to a mode of action to treat a pathology group identified by the ATC3 level,

\begin{tabular}{|c|c|c|c|c|c|}
\hline ATC3 class & ATC4 class & Description & Molecule Name & Brand Name & Patent Expiry \\
\hline \multirow[t]{6}{*}{ C10A } & \multirow[t]{6}{*}{ C10A1 } & \multirow[t]{6}{*}{ Statins } & Atorvastatin & Lipitor & \multirow{3}{*}{ withdrawn 2001} \\
\hline & & & Cerivastatin & Lipobay & \\
\hline & & & Fluvastatin & Lescol & \\
\hline & & & Lovastatin & Mevacor & \multirow{3}{*}{$2001 q 4$} \\
\hline & & & Pravastatin & Pravachol & \\
\hline & & & Simvastatin & Zocor & \\
\hline \multirow[t]{4}{*}{ C10A } & \multirow[t]{4}{*}{ C10A3 } & Bile Acid & Colestipol & Colestid & \multirow{4}{*}{$1996 \mathrm{q} 3$} \\
\hline & & Sequestrant & Cholestyramine & Questran & \\
\hline & & & $\begin{array}{l}\text { Aspartame+ } \\
\text { colestyramine }\end{array}$ & Prevalide & \\
\hline & & & Colesevelam & Welchol & \\
\hline
\end{tabular}

Table 2. Classification of Anti-cholesterol Drugs

\footnotetext{
${ }^{19}$ Statins (C10A1) lower cholesterol levels by inhibiting the enzyme HMG-CoA reductase, which plays a central role in the production of cholesterol in the liver. Bile Acid Sequestrants (C10A3) increase the elimination of bile acids which the liver can replace only by converting cholesterol, thus reducing its level in the blood. Note that there are other ATC4 groups in the therapeutic market C10A, such as Fibrates (C10A2). Although we observe quantities and prices for Fibrates, we have promotional data only for the most important ATC4 markets. In fact, quarterly sales of Fibrates in 2000 were around ten million dollars compared to quarterly sales of more than a billion dollars for Statins.
} 
we conjecture that the higher the number of ATC4 subclasses in an ATC3 market, the more differentiation there is. ${ }^{20}$ We therefore define $M o A$ (for Modes of Action) as the number of ATC4 subclasses in each ATC3 market, minus 1. That is, for each drug, we identify the number of rival modes of action to treat the same pathology. We assess whether this variable appropriately captures horizontal differentiation in the empirical analysis.

\section{Price, Market Share, and Promotion}

For each of the drugs included in the selected markets, we compute deflated revenues $(R)$ by dividing nominal value of sales by the producer price index for the pharmaceutical industry published by the Bureau of Labor Statistics. Quantities $(Q)$ are reported in standard units that represent the number of dose units sold for each product; this corresponds to one capsule or tablet of the smallest dosage or five milliliters of a liquid (i.e., one teaspoon). Standard units allow comparison across different drug forms and dosages, as all different packages are subsumed into the same unit of observation. We then compute the average price of a molecule $(P)$ by dividing $R$-i.e., the revenues for all the different packages - by total $Q .{ }^{21}$ An important feature of our data is that we observe $R$ and $Q$ for two different distribution channels: hospital $(\mathrm{HO})$ and pharmacies $(\mathrm{PH})$.

Promotional data include three main components: visits to office-based practitioners and hospital specialists (aka "detailing"); free samples dispensed to physicians (their cost being estimated as the sales price of the drug); and advertising in professional journals. IMS Health data on detailing are constructed using a representative panel of physicians who track their contacts with sales representatives. The amount spent on free samples is based on a panel of approximately 1200 office staff members in medical practices, while expenditures on advertising in professional journals are computed by tracking ads placed in approximately 400 medical journals and then adding the publisher's charge for those ads. The empirical analysis assumes that promotion to office-based practitioners affects sales in pharmacies, while promotion to hospital physicians affects the use of drugs in hospitals.

\footnotetext{
${ }^{20}$ Dubois and Lasio (2017, Table 6) managed to estimate cross-price elasticities for each pair of molecules in one ATC3 market. They do report high cross-price elasticities within an ATC4 market, and close to zero elasticities across ATC4 subclasses.

${ }^{21}$ This produces a price per standard unit. Note that our empirical specifications control for unobserved differences, such as quality and Defined Daily Dose (DDD), across molecules.
} 
The promotion level used in the demand specifications reported in Section 5 is computed with the perpetual inventory method, commonly used for physical capital:

$$
A_{i t}=(1-\rho) A_{i t-1}+I_{i t},
$$

where $I_{i t}$ is the quarterly expenditure in promotion retrieved from IMS, and $\rho$ is the quarterly depreciation rate, assumed to be $0.1-i$.e., about $35 \%$ per year. ${ }^{22}$

Table 3 reports descriptive statistics for these variables, distinguishing between hospitals and pharmacies. Note that competitors' promotion refers to the sum of the promotion of all other drugs in the ATC3 market, each computed according to the equation above. At the same time, the competitors' price refers to the average price of all the other molecules in the market, including generics, and it is computed as the ratio between total revenues and total quantities in the ATC3 market, after subtracting the revenues and quantities of drug $i$.

\begin{tabular}{cccccc}
\hline \hline Variables & Channel & Mean & SD & Min & Max \\
\hline \multirow{2}{*}{ Market Shares } & Hosp & 0.117 & 0.173 & 0.01 & 1 \\
& Phar & 0.134 & 0.183 & 0.01 & 1 \\
\hline \# Competitors & Hosp & 13.2 & 8.17 & 0 & 46 \\
(other Molecules) & Phar & 12.1 & 6.62 & 0 & 41 \\
\hline \multirow{2}{*}{ Own Price } & Hosp & 16.73 & 70.31 & 0.02 & 902.8 \\
& Phar & 16.78 & 71.23 & 0.05 & 910.1 \\
\hline \multirow{2}{*}{ Own Promotion } & Hosp & 3269 & 8101 & 0 & 59469 \\
& Phar & 11165 & 24592 & 0 & 198027 \\
\hline Competitors' Price & Hosp & 8.86 & 28.32 & 0.02 & 197.29 \\
(average price in ATC3) & Phar & 4.15 & 15.19 & 0.02 & 122.13 \\
\hline Competitors' Promotion & Hosp & 16315 & 37402 & 0 & 231144 \\
(total promotion in ATC3) & Phar & 55871 & 124654 & 0 & 891515 \\
\hline \hline
\end{tabular}

Table 3. Summary Statistics

To get an initial grasp of the differences between hospitals and pharmacies, the upper part of Table 4 shows that the volume of drugs dispensed in pharmacies is three times as high as in hospitals. The bottom part reports two different statistics for the drop in volume market shares following generic entry: ${ }^{23} i$ ) the simple average and $\left.i i\right)$ the average where each

\footnotetext{
${ }^{22}$ All the results reported in Section 5 are robust to setting $\rho=0.3$.

${ }^{23}$ The changes are calculated based on the evolution between three years before and after patent expiration. When patent expiration is close either to the beginning or to the end of the sample period 1994Q1-2003Q4, we take the first (last) available observation for the pre-expiration (post-expiration) period.
} 
molecule has been weighted by the advertising intensity of competitors in the same ATC3. Table 4 suggests that drops in market shares observed after LoE are more pronounced in pharmacies and in markets in which promotion is more prevalent. We will exploit these dimensions of heterogeneity in the econometric analysis.

\begin{tabular}{lcc}
\hline \hline Distribution of $Q_{P H} /\left(Q_{P H}+Q_{H O}\right)$ & & \\
Mean & 0.75 & \\
Median & 0.86 & \\
\hline \hline Percentage Change before and after Patent Expiration & $P H$ & $H O$ \\
Market Shares: & & \\
Simple Mean & -0.31 & -0.26 \\
Weighted by Drug-A Sales & -0.36 & -0.25 \\
Weighted by ATC3 promotion & -0.40 & -0.35 \\
\hline Price & -0.44 & -0.45 \\
Advertising & -0.89 & -0.85 \\
\hline \hline
\end{tabular}

Table 4. Distribution: Pharmacists (PH) \& Hospitals (HO)

\section{$5 \quad$ Empirical Analysis}

In this section, we first establish whether our theoretical assumptions about the demand side are confirmed in the data (Section 5.1). We then move to our core contribution, which is to assess the model's testable implications regarding market reactions to generic entry (Section $5.2)$.

\subsection{Demand prior to LoE: hospitals and pharmacies}

In this subsection, we assess the relative importance of prices and promotion, separately for the hospital and the pharmacy channel. For this, we estimate the elasticity of a given branded drug's market share with respect to its own price and promotion effort, as well as the cross-elasticities for competing drugs, using an unbalanced panel of active ingredients until one quarter before LoE. ${ }^{24,25}$ We also compare these "cross" coefficients between ATC3

\footnotetext{
${ }^{24}$ This means that all firms in this subsample face competition only from imperfect substitutes (that can be generic or branded).

${ }^{25}$ Note that our aim is not to retrieve price-cost margins, or to carry out merger simulations, for which other more sophisticated models of differentiated products demand - e.g. Almost Ideal Demand System, nested logit
} 
markets made up of either a single or various ATC4 sub-markets.

Anticipating, we find that the elasticity of demand is higher in hospitals. This result is then used in Section 5.2 to evaluate our first testable implication.

For any ATC market $j$, equation (7) describes the P3s' demand for a particular molecule $i$ at time $t$. The demand equation is estimated in first-differences in order to remove all time-invariant, drug-specific fixed effects, such as quality differences: ${ }^{26}$

$$
\begin{aligned}
\Delta m s_{i, j, t}= & \alpha_{0}+\alpha_{1} \Delta p_{i, j, t}+\alpha_{2} \Delta a_{i, j, t}+\alpha_{3} \Delta p_{-i, j, t}+\alpha_{4} \Delta a_{-i, j, t} \\
& +\alpha_{5} \Delta G E N_{j, t}+\alpha_{6} \Delta N C_{j, t}+\alpha_{7} T E_{i, j, t}+\varepsilon_{i, j, t}
\end{aligned}
$$

where $\Delta m s_{i, j, t}, \Delta p_{i, j, t}$ and $\Delta a_{i, j, t}$ respectively refer to the change in the logs, i.e., quarterly growth of quantity market share, price, and promotion effort of branded drug $i$ in ATC3 market $j$ (to repeat, our unbalanced panel includes molecules $i$ until one quarter before LoE). Similarly, $\Delta p_{-i, j, t}$ and $\Delta a_{-i, j, t}$ are the competing molecules' evolution of prices and promotion in the same ATC3 market (the products in $-i$ may either be branded or generic). All of these variables are in logarithms, implying that the coefficients can be interpreted as (short-term) elasticities - see Section 6.3 for a discussion.

To explore whether there are substantial differences between ATC3 markets with a single or with multiple modes of action, we estimate two cross-price elasticities, $\alpha_{3}^{1}$ and $\alpha_{3}^{2+}$. The former pertains to ATC3 markets with only one ATC4, while the latter is obtained for ATC3 markets with more than one ATC4. We make the same distinction for competitors' promotion $\left(\alpha_{4}^{1}\right.$ vs. $\left.\alpha_{4}^{2+}\right)$. This allows us to assess the validity of defining markets at the ATC3 level. In addition, the estimates of $\alpha_{3}^{1}$ and $\alpha_{3}^{2+}$ also shed light on whether $M o A$ is an appropriate measure of horizontal differentiation.

$\triangle G E N$ is an indicator variable that takes value 1 in each of the four quarters after the generization of a competing molecule. This variable captures changes in the competitive landscape of market $j$ caused by the entry of a new generic competitor. We do not expect it to be significant: according to our hypotheses, generic entry affects demand only through its

or random coefficient models would be better suited.

${ }^{26}$ Results using FE are qualitatively similar, but we could not identify a set of instruments that simultaneously pass the relevant tests for under-identification/weak-identification and the Hansen $J$ test for the exogeneity (orthogonality) of the instruments. 
effect on prices and promotional effort. Similarly to $\Delta G E N$, the variable $\Delta N C$ takes value 1 in the first four quarters after a new competing drug is launched on the market. Finally, the variable $T E$ (Time to Expiration) counts the number of quarters left to patent expiration, to account for the impact of the drug's life cycle on demand. ${ }^{27}$ In this and all the other estimations reported in the remainder of this paper, errors have been clustered at the ATC3 level.

The regressors are likely affected by two different problems. The first one is that feedback from market-share shocks to future prices and advertising may produce endogeneity issues (reverse causality). The second problem is errors in the measurement of both prices and promotion effort. The price actually paid may differ from the price we observe in the IMS database because the latter does not reflect off-invoice ex-post rebates that pharmaceutical companies grant to large buyers in return for some performance component, such as reaching a target volume of sales (see Berndt (2012) and footnote 34). Errors in the measurement of promotion effort stem from the difficulty to observe and quantify monetarily the work of sales representatives when they visit physicians. Both measurement errors are likely to create an attenuation bias when estimating (7) using OLS. ${ }^{28}$

To address these two problems, we instrument prices and promotion expenditure with three sets of instruments. The first is the number of packages, linear and squared, following Chaudhuri, Goldberg and Gia (2006). As they argue, the number of packages is related to the price $p$ because variations in $p$ stem in part from variations in the set of packages available in each period. An advantage of our dataset over theirs is that we can also control for promotional effort. The introduction of a new posology or delivery mode is likely to be accompanied by a resurgence in promotional effort, if only in the form of free samples to doctors. ${ }^{29}$ As IMS data on promotion include an estimate of free samples, this instrument

\footnotetext{
${ }^{27}$ We use negative values so that the variable is increasing as we approach patent expiration. For instance, -10 and -1 refer, respectively, to ten quarters and one quarter before LoE.

${ }^{28}$ In the words of Griliches and Hausman (1986), "Errors of measurement will usually bias the first difference estimators downward (toward zero) by more than they will bias the within estimators." This problem has been largely discussed in the empirical literature on the estimation of production function (see Griliches and Mairesse (1995), among others). It is not by coincidence that the estimation of the demand elasticity to promotion is affected by the same problem of the elasticity of production with respect to capital. In fact, in both cases, econometricians need to construct a measure of "effective stock" looking at data on past and present expenditures on physical capital or promotional effort.

${ }^{29}$ For instance, Ely Lilly started a intense marketing campaign to promote Prozac Weekly, a once-weekly
} 
should be highly correlated with promotion expenditures but plausibly uncorrelated with the measurement error, since the number of packages is measured accurately. The second set of instruments follows the approach proposed by Dubois and Lasio (2018). ${ }^{30}$ We use two variants of their approach. First, we use the residuals of the regression of prices in hospitals (respectively: pharmacies) over firms' promotion, molecule dummies and time fixed effects as an instrument for the pharmacy (resp., hospital) channel. Second, we use the residuals of the regressions of prices in the United Kingdom over molecule dummies and time fixed effects to instrument for the corresponding channel in the United States. The third set of instruments consists of an indicator for the launch of a new product by the same company and a dummy indicating whether a branded drug has experienced the entry of a generic competitor before LoE, following a successful "Paragraph IV" challenge. ${ }^{31}$

This choice of instruments is validated by the Kleibergen-Paap $r k$-statistic (K-P) for under-identification, the Angrist-Pischke (A-P) F-test for weak instruments, the Hansen $J$ test for the orthogonality conditions, and the $C$-statistic to test the exogeneity (endogeneity) of one or more instruments (regressors). ${ }^{32}$

\section{Regression Results}

We estimate the empirical model in (7) separately for hospitals and pharmacies in order to assess whether these two channels react differently to variations in prices and promotion. ${ }^{33}$ Columns (1) and (4) of Table 5 report the estimates obtained without instrumenting for

formulation of Prozac. Another example is Paxil CR, a controlled-release version of Paxil. Other examples abound.

${ }^{30}$ They note that "Controlling for country and time effects, we isolate the quality of each drug proxied by molecule dummies, which is the part of the price more likely to be correlated with demand unobservables: what remains is supposed to be correlated with the marginal cost of each drug."

${ }^{31}$ Paragraph IV of the Hatch-Waxman Act allows generic manufacturers to attempt to enter the market before patent expiration of the original branded drug, either by claiming non-infringement or invalidity of the branded product's patent. A successful Paragraph-IV challenge represents an exogenous shift in the promotional effort of branded drugs uncorrelated with demand shocks or measurement errors. Branstetter, Chatterjee and Higgins (2011) investigate the welfare effect of accelerated generic entry via Para-IV challenges for hypertensive drugs.

${ }^{32}$ Our IV strategy is also supported by the fact that our estimates of price-elasticities are lower but not too far off the order of magnitude reported by Dubois and Lasio (2017). They use IMS data for France, where problems of measurement errors, and the resulting attenuation bias, are less important given the regulatory constraints on the pharmaceutical industry.

${ }^{33}$ Berndt (2002) provides a detailed explanation as to why arbitrage between different channels (here: hospitals and retail pharmacies) cannot occur. 


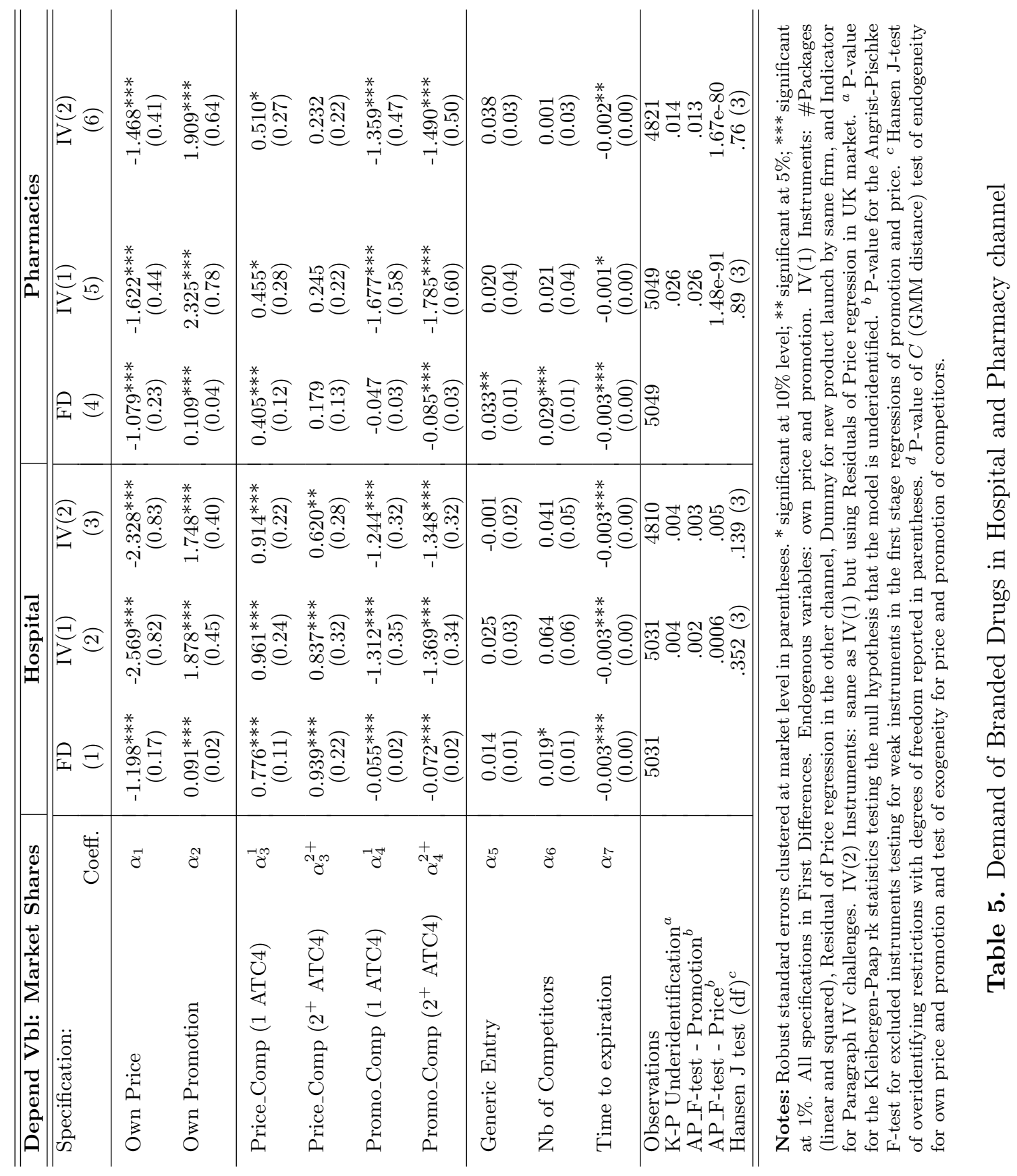


prices and promotion. Comparing these results with those in Columns (2 and 3) and (4 and 5) confirms the existence of an attenuation bias due to errors in measuring prices and promotion intensity. They also reveal price and promotion elasticities that are in the upper range of those found in the literature (but see footnote 32). Section 6.3 explains why these elasticities ought to appropriately capture the effects of price and promotion movements associated with generic entry.

A number of findings emerge from the IV results. First, the estimated elasticity w.r.t. own-price is higher in hospitals than in pharmacies. Second, the coefficients pertaining to the price of competitors (Price_Comp), $\alpha_{3}^{1}$ and $\alpha_{3}^{2+}$, are significantly larger and more precisely estimated in the hospital channel. Third, for pharmacies, only $\alpha_{3}^{1}$ is significant (and at the $10 \%$ level). Overall, these findings reinforce the message that hospitals are more pricesensitive than private practice doctors.

This difference is in line with Inderst and Ottaviani (2012)'s intuition: private practice doctors do not directly benefit when patients buy a cheaper alternative (possibly, they even lose some perks offered by pharmaceutical companies) and, at the same time, these patients only pay a fraction of the drug's price, thanks to third-party payer coverage. By contrast, hospitals are residual claimants: their margin depends one-for-one on procuring drugs at a discount since they then charge the patient a pre-determined reference price. ${ }^{34}$

Fourth, we find that the elasticities for own- and cross-promotion are of the right sign, large, and precisely estimated in both channels. When instrumented, the point estimates increase substantially, confirming the extent to which this variable is affected by endogeneity problems. Interestingly enough, the two coefficients $\alpha_{4}^{1}$ and $\alpha_{4}^{2+}$ are similar both within and between channels.

Fifth, the overall picture that emerges from the above results is that the ATC3 level appropriately represents a molecule's market even if price competition appears more subdued across ATC4 sub-classes. The latter observation suggests that coexistence of different modes of action within a market should be a good proxy for horizontal differentiation.

\footnotetext{
34 This is also in line with the patterns evidenced by Berndt (2002, p60): "Next lowest are prices to hospitals for inpatient prescription use only [...] [P] rices charged retail pharmacies for their cash-paying customers are discounted off "list" price the least".
} 
The coefficients on the headcount of genericized molecules and on the number of competitors are statistically insignificant once we properly control for endogeneity. These results confirm the working assumptions made in our model: (a) generic entry affects demand through the price and promotion of a given molecule. (b) Market share movements of incumbents are not driven by the launch of new molecules above and beyond the latter's effects on price and promotion.

\subsection{The effects of generic entry (testable implications 1-3)}

The previous section produced three results that are important to test the predictions of the model. First, the ATC3 level is a reasonable definition of a therapeutic market. Second, the variable $M o A$ (modes of action, see p20) qualifies as a proxy for horizontal differentiation within a market. Third, hospitals are comparatively more price sensitive than pharmacies. In addition, we can control for other time-invariant differences (such as vertical differentiation) through molecule fixed effects.

Adding a variable to capture market size, we have all the elements needed to evaluate testable implications 1-3:

$$
\begin{aligned}
y_{i, j, c, t}= & \gamma_{1} G E N_{j, t}+\gamma_{2} \operatorname{Hosp} G E N_{j, t}+\gamma_{3} \operatorname{MoA}_{t} G E N_{j, t} \\
& +\gamma_{4} \operatorname{Small}_{i} G E N_{j, t}+\rho y_{i, j, c, t-4}+\beta^{\prime} X_{i, j, c, t}+\alpha_{i}+\varepsilon_{i, j, c, t}
\end{aligned}
$$

where $y_{i, j, c, t} \in\{m s, a, p\}$ is the log of either the market share, promotion level, or price, of the patent-protected drug $i$ in ATC3 market $j$ sold in channel $c \in\{$ Hospital, Pharmacy $\}$, at time t. $G E N_{j, t}$ counts the number of molecules that lost exclusivity in the same market. Hosp is a dummy for the hospital channel, and $M o A_{t}$ is our proxy for horizontal differentiation. To test for the effect of market size (testable implication 3), we distinguish between a "blockbuster" group, defined as the set of the top $25 \%$ selling drugs during the entire time period, and the remaining $75 \%$, which we identify with the indicator variable $\operatorname{Small}_{i}$.

To check the robustness of our results, we also rely on an alternative count measure of generic entries, by discarding the LoE events that concerned low-selling products. More precisely, we only count the LoEs of the 20 drugs (out of 95) with the largest average sales 
over the sample period. We will refer to this variable as $G E N^{I M P}$, for IMPortant generic entries.

Equation (8) also includes the one-year lag of the dependent variable (i.e., four quarters) to capture dynamic autoregressive processes, such as possible seasonal variations in drug usage over the year (e.g. antibiotics and antihistamines). The set of control variables $X$ includes the number of competing molecules to proxy the intensity of competition, time to expiration, and a complete set of time dummies. As for other specifications, the data for $y$ pertain to branded drugs until one quarter before patent expiration.

According to testable implication 1, following the LoE of some molecule $A$, the market share of an on-patent molecule $B$ should increase less (or decrease more) if $\delta$ is higher. In light of the results of Section 5.1, that elasticity is higher in hospitals. We thus expect $\gamma_{2}$ to be negative. According to testable implication 2, we expect $\gamma_{3}$ to be negative: the market share of molecule $B$ should increase less (or decrease more) if the ATC3 market features more horizontal differentiation. Finally, testable implication 3 predicts that $\gamma_{4}$ should be negative: on-patent $\operatorname{drug} B$ should be more likely to lose market share if the revenue it generated is small prior to LoE.

Column 1 and 2 of Table 6 reports the FE estimates with market share as the dependent variable. All the coefficients have the expected signs and they are all significant at $5 \%$ level, with the exception of $\gamma_{2}$ in column 1 . The coefficients in column (2) show that, when we restrict the analysis to the most important cases of generic entry, there is a substantial increase in the magnitude of the point estimates, and $\gamma_{2}$ also becomes significant at the $5 \%$ level. Yet, the relative magnitude of the coefficients remains similar. Overall, these estimates are consistent with our testable implications. First, we observe mainly instances of branded drugs increasing their volume market share following the genericization of a competitor: $\gamma_{1}$ is positive and significant. As we detail in Section 6.3, the impact of generic entry on promotional effort and prices is an important factor to explain this evolution.

Second, and in line with testable implication 1, the higher elasticity of demand in the hospital channel reduces the market share gain by a quarter for the drugs remaining on patent: in column (2), the coefficient on $H O S P * G E N$ is negative, significant, and equal to a fourth of $\gamma_{1}$. In line with testable implication 2 , the negative coefficient $\gamma_{3}$ confirms 


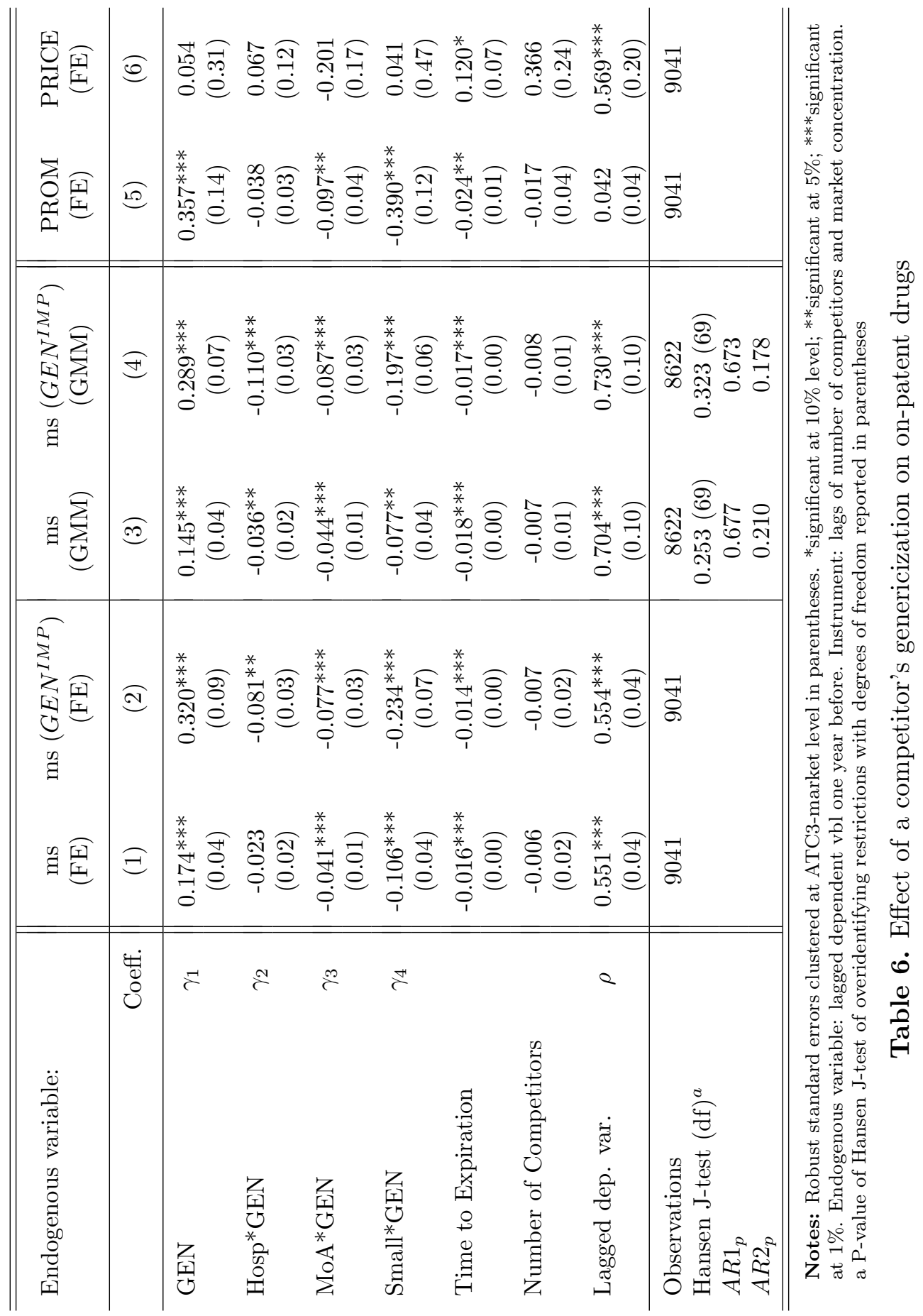


that markets characterized by higher horizontal differentiation experience a smaller increase in market share. The interaction between the revenue size indicator variable and the generic count $\left(\gamma_{4}\right)$ is also significant and of the expected sign, confirming testable implication 3.

Our testable implications should also apply to promotion and prices. The results are presented in columns 5 and 6: we find that promotion reacts in the same way as market shares, although by a larger magnitude. By contrast, the coefficients for prices are not significant. This reinforces the overall message that promotion is the privileged mode of competitive interactions, while it may be more difficult to increase prices-which have probably been previously negotiated with third party payers - each time a generic enters the market. ${ }^{35}$

Because of the presence of the lagged dependent variable, the use of fixed effects leads to a downward bias (known as "Nickell bias") in the point estimate of $\rho$, which can be transmitted to the other coefficients. Although this bias is small in dataset with large $T$. We check the robustness of our results given the unbalanced nature of our dataset. To this end, we use the GMM estimator with the forward orthogonal deviation (FOD) transformation proposed by Arellano and Bover (1995). An important advantage of FOD is that, unlike the First-Difference estimator which introduces a moving average structure in the error term, the lack of correlation in the transformed errors is preserved if the original ones are not autocorrelated. The instruments we use are composed of lags of the number of competitors and the Herfindahl-Hirschman concentration index. ${ }^{36}$ Because the number of instruments generated by our GMM framework is quadratic in $T$, we avoid the problem of using "too many weak instruments" by using the collapse option as explained in Roodman (2006). The statistical tests reported at the end of Table 6 support our IV strategy. As expected, the coefficient on the lagged dependent variables in columns (3) and (4) is now higher. Overall, the IV approach confirms and reinforces the FE results, without affecting the magnitude of the other coefficients.

\footnotetext{
${ }^{35}$ Moreover, as emphasized on p.24, we cannot observe price rebates, which probably are the easiest-to-use margin of adjustment for actual sale prices.

${ }^{36}$ For each specification, we also experimented with additional lags of the dependent variable. While the results were qualitatively similar, the Hansen test was often not passed.
} 


\section{Robustness and sensitivity}

This section addresses three issues. First, we check whether our results are robust to evergreening strategies. We do this by reestimating our demand equation (7) excluding instances of LoE experienced by a drug whose originator also owned a second-generation product in the same market. We also reestimate equation (8) to check whether evergreening amplifies the migration to on-patent drugs. Second, we investigate the stability of the coefficients of the demand equation to changes in the set of instruments. Finally, we assess whether the elasticities reported in Table 5 do a good job in predicting observed post LoE developments. In addition, we compare these estimates with those typically found in the literature.

\subsection{Evergreening}

As detailed in Section 2, "evergreening" refers to the introduction of second-generation versions of the drugs by the very firm that faces the loss of exclusivity on a drug. The European Commission's Pharmaceutical Sector Inquiry identified a related tactic, which is to withdraw the first-generation product soon after the launch of the second generation product and before LoE for the first generation product (SI, p.365).

One may argue that this is the main rationale for the reduction in market shares of the molecules losing exclusivity, instead of generic competition. We instead contend that evergreening is just an instance in which the firm losing exclusivity and the one proposing a branded substitute are the same. The logic of organizing the transfer of patients via an intense promotion campaign is the same; the confluence of interests should only make the effects stronger. Hence, the mechanism we document is not incompatible with evergreening. On the contrary, the rationale underpinning evergreening strategies requires that promotion be effective. ${ }^{37}$

In our dataset, we observe twenty cases where the originator facing generic entry also

\footnotetext{
${ }^{37}$ One originator (EC Sector Inquiry, p.360, \#1028) reported: "This means each patient that is not switched quickly enough to [our second generation product] is forever lost to the generics. Once the patient is switched to [our second generation product] the physician does not have to, cannot and will not switch him to a generic, and what is more important: the pharmacist cannot substitute!" Figure 138, p. 361 of the SI indicates that most second generation launches occur prior to the first generation product experiencing LoE.
} 


\begin{tabular}{|c|c|c|c|c|c|}
\hline \multicolumn{2}{|c|}{ Depend Vbl: Market Shares } & \multicolumn{2}{|c|}{ Hospital } & \multicolumn{2}{|c|}{ Pharmacies } \\
\hline Specification: & Coeff. & $\begin{array}{l}\text { FD } \\
(1)\end{array}$ & $\begin{array}{c}\text { FD-IV } \\
(2)\end{array}$ & $\begin{array}{l}\text { FD } \\
(3)\end{array}$ & $\begin{array}{c}\text { FD-IV } \\
(4)\end{array}$ \\
\hline Own Price & $\alpha_{1}$ & $\begin{array}{c}-1.156^{* * *} \\
(0.17)\end{array}$ & $\begin{array}{c}-2.080^{* * *} \\
(0.77)\end{array}$ & $\begin{array}{c}-1.082^{* * *} \\
(0.24)\end{array}$ & $\begin{array}{c}-1.864^{* * *} \\
(0.55)\end{array}$ \\
\hline Own promotion & $\alpha_{2}$ & $\begin{array}{c}0.091^{* * * *} \\
(0.03)\end{array}$ & $\begin{array}{c}1.542^{* * * *} \\
(0.39)\end{array}$ & $\begin{array}{c}0.099 * * \\
(0.04)\end{array}$ & $\begin{array}{c}1.830 * * * \\
(0.60)\end{array}$ \\
\hline Price_Comp (1 ATC4) & $\alpha_{3}^{1}$ & $\begin{array}{c}0.757^{* * *} \\
(0.12)\end{array}$ & $\begin{array}{c}0.898^{* * * *} \\
(0.22)\end{array}$ & $\begin{array}{c}0.421^{* *} \\
(0.12)\end{array}$ & $\begin{array}{c}0.534^{*} \\
(0.29)\end{array}$ \\
\hline Price_Comp $\left(2^{+}\right.$ATC4 $)$ & $\alpha_{3}^{2+}$ & $\begin{array}{c}1.003^{* * *} \\
(0.25)\end{array}$ & $\begin{array}{c}0.608 * * \\
(0.30)\end{array}$ & $\begin{array}{l}0.212 \\
(0.14)\end{array}$ & $\begin{array}{l}0.264 \\
(0.22)\end{array}$ \\
\hline Promo_Comp (1 ATC4) & $\alpha_{4}^{1}$ & $\begin{array}{c}-0.062^{* * *} \\
(0.02)\end{array}$ & $\begin{array}{c}-1.116^{* * *} \\
(0.33)\end{array}$ & $\begin{array}{l}-0.035 \\
(0.04)\end{array}$ & $\begin{array}{c}-1.270^{* * *} \\
(0.45)\end{array}$ \\
\hline Promo_Comp $\left(2^{+}\right.$ATC4 $)$ & $\alpha_{4}^{2+}$ & $\begin{array}{c}-0.071^{* * *} * \\
(0.02)\end{array}$ & $\begin{array}{c}-1.171^{* * *} \\
(0.31)\end{array}$ & $\begin{array}{c}-0.076^{* *} \\
(0.03)\end{array}$ & $\begin{array}{c}-1.387^{* * *} * \\
(0.46)\end{array}$ \\
\hline Generic Entry & $\alpha_{5}$ & $\begin{array}{c}0.010 \\
(0.01)\end{array}$ & $\begin{array}{r}-0.001 \\
(0.02)\end{array}$ & $\begin{array}{c}0.030^{* *} \\
(0.01)\end{array}$ & $\begin{array}{c}0.028 \\
(0.03)\end{array}$ \\
\hline Nmb of Competitors & $\alpha_{6}$ & $\begin{array}{c}0.020^{*} \\
(0.01)\end{array}$ & $\begin{array}{l}0.022 \\
(0.05)\end{array}$ & $\begin{array}{c}0.031^{* * *} \\
(0.01)\end{array}$ & $\begin{array}{l}0.005 \\
(0.03)\end{array}$ \\
\hline Time to Expiration & & $\begin{array}{c}-0.003^{* * *} \\
(0.00)\end{array}$ & $\begin{array}{c}-0.003^{* * *} \\
(0.00)\end{array}$ & $\begin{array}{c}-0.003^{* * *} \\
(0.00)\end{array}$ & $\begin{array}{c}-0.002^{* *} \\
(0.00)\end{array}$ \\
\hline $\begin{array}{l}\text { Observations } \\
\text { K-P Underidentification } \\
{ }^{a} \\
\text { AP_F-test - Promotion } \\
\text { AP_F-test - Price } \\
\text { Hansen J test (df) }{ }^{c}\end{array}$ & & 4556 & $\begin{array}{l}4335 \\
.0077 \\
.0053 \\
.0083 \\
.253(3) \\
\end{array}$ & 4576 & $\begin{array}{l}4348 \\
.0397 \\
.0348 \\
.0001 \\
.583(3) \\
\end{array}$ \\
\hline
\end{tabular}

Notes: Robust standard errors clustered at market level in parentheses. ${ }^{*}$ significant at $10 \%$ level; ** significant at $5 \%$; *** significant at $1 \%$. All specifications in First Differences. Endogenous variables: Own price and promotion. IV Instruments: \#Packages (linear and squared), Residual of Price regression in UK market, Dummy for new product launch by same firm, and Indicator for Paragraph IV challenges. ${ }^{a}$ P-value for the Kleibergen-Paap rk statistics testing the null hypothesis that the model is underidentified. ${ }^{b} \mathrm{P}$-value for the Angrist-Pischke F-test for excluded instruments testing for weak instruments in the first stage regressions of promotion and price. ${ }^{c}$ Hansen J-test of overidentifying restrictions with degrees of freedom reported in parentheses. ${ }^{d} \mathrm{P}$-value of $C$ (GMM distance) test of endogeneity for own price and promotion and test of exogeneity for price and promotion of competitors.

Table 5b. Demand for Branded Drugs: Sample Excluding Evergreening Episodes 
owns one or more on-patent drugs in the same ATC3 market. ${ }^{38}$ To assess the validity of our argument, we re-estimate equation (8) excluding the episodes of generic entry in which the firm that experiences the LoE episode also owned marketing rights for another drug in the same ATC3. This shrinks our sample size by about $10 \%$, which reduces the significance of some coefficients.

The results are presented in Table 5b: in comparison with Table 5, the coefficients on own and competitors' promotion remain largely unchanged. This provides strong support to the idea that ever-greening is not the whole story behind the market share loss of molecules losing exclusivity.

In Table 6b, we re-estimate specifications (1) and (3) in Table 6, which use market shares

\begin{tabular}{|c|c|c|c|}
\hline & Coef. & $\begin{array}{l}\mathrm{FE} \\
(1) \\
\end{array}$ & $\begin{array}{c}\text { GMM } \\
(2)\end{array}$ \\
\hline$G E N_{N E v e r G}$ & $\gamma_{1_{N E G}}$ & $\begin{array}{c}0.163^{* * *} \\
(0.04)\end{array}$ & $\begin{array}{c}0.138^{* * *} * \\
(0.04)\end{array}$ \\
\hline$G E N_{E v e r G}$ & $\gamma_{1_{E G}}$ & $\begin{array}{c}0.272^{* * *} \\
(0.07)\end{array}$ & $\begin{array}{c}0.234^{* * *} \\
(0.06)\end{array}$ \\
\hline$H o s p * G E N$ & $\gamma_{2}$ & $\begin{array}{c}-0.020 \\
(0.02)\end{array}$ & $\begin{array}{c}-0.033^{*} \\
(0.02)\end{array}$ \\
\hline$M o A * G E N$ & $\gamma_{3}$ & $\begin{array}{c}-0.040^{* * * *} \\
(0.01)\end{array}$ & $\begin{array}{c}-0.043^{* * *} \\
(0.01)\end{array}$ \\
\hline Small $* G E N$ & $\gamma_{4}$ & $\begin{array}{c}-0.111^{* * * *} \\
(0.04)\end{array}$ & $\begin{array}{c}-0.084^{* *} \\
(0.04)\end{array}$ \\
\hline Time to expiry & & $\begin{array}{c}-0.017^{* * *} \\
(0.00)\end{array}$ & $\begin{array}{c}-0.018^{* * * *} \\
(0.00)\end{array}$ \\
\hline \# competitors & & $\begin{array}{c}-0.008 \\
(0.02)\end{array}$ & $\begin{array}{c}-0.008 \\
(0.01)\end{array}$ \\
\hline Lagged mkt share & $\rho$ & $\begin{array}{c}0.550^{* * * *} \\
(0.04)\end{array}$ & $\begin{array}{c}0.690 * * * \\
(0.10)\end{array}$ \\
\hline $\begin{array}{l}\text { Obs } \\
\text { Hansen p-value (df) } \\
\text { AR } 1_{p} \\
\operatorname{AR} 2_{p}\end{array}$ & & 9041 & $\begin{array}{c}8622 \\
0.20(69) \\
0.673 \\
0.240\end{array}$ \\
\hline
\end{tabular}

Notes: Robust std errors clustered at ATC3-market level in parentheses. *significant at $10 \%$ level; ${ }^{* *}$ significant at $5 \%$; ***significant at $1 \%$. Endogenous variable: lagged dependent vbl 1 year before. Instruments: lags of \# competitors and market concentration.

\section{Table 6b. Effect of evergreening on on-patent drugs}

\footnotetext{
${ }^{38}$ These include the following two well-know cases: (i) Mevacor (Lovastatin), whose patent expired in 2001, and the follow-on statin Zocor (Simvastatin), both produced by Merck and (ii) Losec (Omeprazole), whose patent expired in 2002, and Nexium (Esomeprazol), both owned by AstraZeneca
} 
as the dependent variable. The difference with Table 6 is that we now distinguish between those instances in which the molecule that loses exclusivity is owned by a company that has another drug in the same ATC3. That is, $G E N_{E v e r G}$ refers to generic entry in markets where the firm losing exclusivity had the opportunity to rely on an evergreening strategy, whereas $G E N_{N E v e r G}$ refers to the other instances of LoE. In line with our conjecture, we find that the coefficient on $G E N_{E v e r G}$ is much larger than the coefficient on $G E N_{N E v e r G}$.

\subsection{Instruments and Robustness of Demand Elasticities}

Here, we discuss two potential concerns about our IV strategy: (1) the residuals of the firststage regression of prices in the other channel or UK prices as dependent variables, may not be orthogonal to firm-wide demand shocks. (2) The results in Table 5 may look stable only because our instruments are highly correlated with each other. To address such concerns and shed additional light on the adequateness of our identification strategy, we repeat the analysis of Table 5 , but with a reduced set of instruments. ${ }^{39}$

Table 5c reports results where we drop: $(i)$ the residuals of the price regression (columns 1); (ii) the number of packages (columns 2); and ( $i i i$ ) the indicator for the introduction of a new product (columns 3).

The specification in column (1) of Table $5 \mathrm{c}$ drops the instruments that could potentially be correlated with firm-wide demand shocks (e.g. in the unlikely case that price variations in the UK are contemporaneously correlated with demand shocks in the US). We find that the results for the hospital channel are extremely stable. Not surprisingly, the fact that we drop the two instruments that are more relevant for prices produces less precise estimates for own-price elasticity in the pharmacy channel. Yet, all the other coefficients are essentially unaffected. The test for under-identification confirms that we have a weak instruments problem in the first-stage regression for prices; hence the choice of instruments used to obtain the results reported in Table 5.

Next, in Section 5.1, we claimed that the number of packages is particularly important to identify the elasticity of demand w.r.t. promotion. To check that this is indeed the case,

\footnotetext{
${ }^{39}$ We thank two anonymous referees for their suggestions. Also, note that a previous version of this paper used average price in other markets (so called "Hausman-type" instruments), which produced similar results.
} 


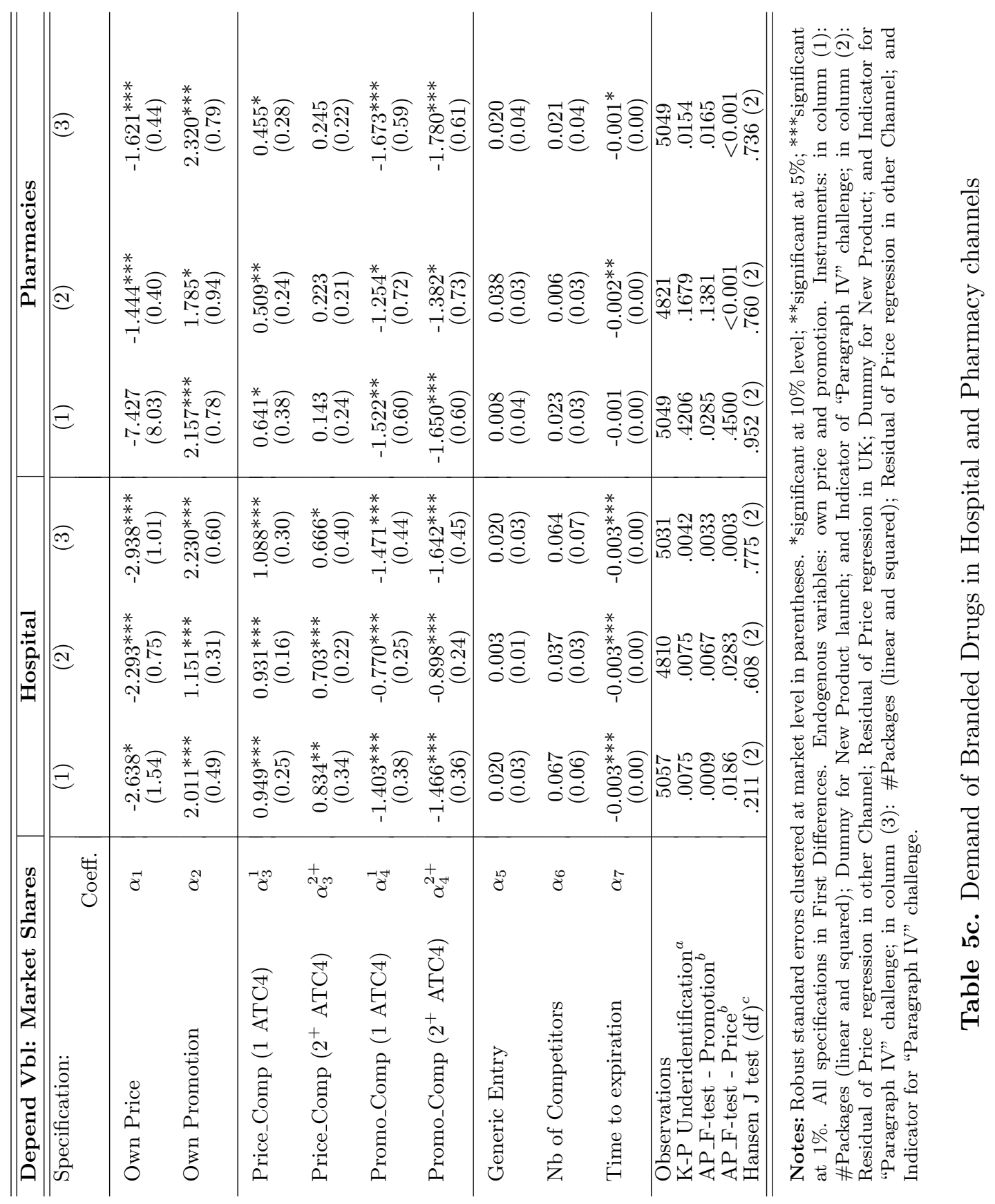


column (2) in Table 5c drops this variable from the set of instruments. In line with our conjecture on identification, we find that the price elasticities are largely unchanged, while the point estimates for promotion are lower in both channels and less precisely estimated in the case of pharmacies. Having dropped our instrument of choice for promotion, the AP F-test for promotion fails in the pharmacy channel; which lends further support to our IV strategy in Table 5. In addition, these results are in line with the conjecture that the pharmacy channel is more sensitive to promotion.

Finally, column (3) drops the indicator for new product launches from the instrument set. The results barely change, although a couple of coefficients are less precisely estimated. This indicates that the information content of this instrument is worth exploiting in the context of our IV strategy. Very similar results (not reported) are obtained when dropping the indicator for Paragraph IV challenges.

Thus, overall, the additional set of results reported in Table $5 \mathrm{c}$ tend to confirm the robustness of our findings, and support our initial choice of instruments. In particular, removing instruments results in under-identification tests that fail, and coefficients on the variables associated to the particular instrument that are less precisely estimated.

\subsection{Assessing demand elasticities: an out-of-sample exercise}

Our estimates for promotion and, to a much lesser extent, price elasticities are in the upper range of what is found in the literature that uses U.S. data, but are not uncommon (see e.g. Narayanan et al. (2005) or Lakdawalla and Philipson (2012, Table 4); see also footnote 32).

We conjecture that there are three main reasons for this: 1) Like Lakdawalla and Philipson (2012) or Dubois and Lasio (2018), our sample covers a long period and includes a large number of LoE events. Patent expiration represents a significant (exogenous) shock that produces a larger-than-usual variation in price and promotional effort. In the presence of switching costs, these are likely to trigger more substantial changes in prescription behavior than temporary or small variations. ${ }^{40}$ 2) We control for both own- and cross-price and

\footnotetext{
${ }^{40}$ Switching costs include for instance having to study the properties of alternative drugs and convincing patients to try them out. Klemperer (1987) shows that even small switching costs can be sufficient for firms to reach fully collusive pricing behavior. Generic entry, in contrast, produces a significant price change, which has the potential to induce a switch. Interestingly, the aforementioned studies of Lakdawalla and Philipson
} 
promotion effects, which addresses a potential omitted-variable bias due to the arms-race nature of promotion. Note that, if the slope of the promotion reaction function is close to 1 (the actual correlation between own and competitor promotion is above 0.6), then the sum of own and cross promotion elasticity yields a figure very close to what is typically reported in the literature. In that respect, it is worth noting that promotion elasticities are typically obtained without including competitors' promotion in the analysis (e.g. Mizik and Jacobson 2004). 3) We use a rich set of instrumental variables: our initial estimates in columns (1) and (4) display significantly lower estimates for promotion elasticities (possibly due to measurement errors in promotion efforts). Moreover, around one third of the drugs in our sample are not actively promoted on the basis of IMS data, which may also contribute to biasing the estimates towards zero. Our instruments appear to address these issues satisfactorily.

Regarding (own) price elasticities, we note that the findings of an elasticity below 1 are difficult to reconcile with profit maximization. By contrast, our point estimates in Table 5, Columns (2) and (5), are compatible with price-cost margins in the $40-55 \%$ range. This order of magnitude is in line with the price reductions observed following generic entry, and it is also close to the results reported by Rizzo (1999), and more recently, by Narayanan et al. (2005). More precisely, the latter report (p.286) own-price elasticities ranging from 2.18 to 2.61 for three antihistaminics. ${ }^{41}$

With regard to promotion elasticities, the meta-analysis by Kremer et al. (2008) reports that estimates ranging from a negative value (Venkataraman and Stremersch 2007) and 1.39 (Berndt, Pindyck and Azoulay 2003), and the average of all estimates is 0.35. More recently, Dave and Saffer (2012, Table 2) report an elasticity w.r.t. detailing comprised between 0.44 and 0.52 . While such elasticities are certainly accurate to describe how prescription behavior reacts to marginal changes in promotion effort (e.g. comparing a doctor who received two visits per month with another who received only one), we argue that they may not appropriately capture the effects of a sustained, nation-wide, promotional effort to influence doctors'

(2012, Table 4) and Dubois and Lasio (2017, Table 4) also capture substantial reactions, which differ from other studies that focus on, say, short-term and minor shocks that are doctor-specific (see e.g. Shapiro 2016). Note that their and our estimates are consistent with each other, despite substantially different estimation strategies, and data coverage.

${ }^{41}$ The elasticities reported by Dubois and Lasio (2017, Table 4) are much higher and range from values of 4.06 for the U.S. and 5.5 for Germany. 
prescription behavior over the long haul.

Formally, we check whether the promotion elasticities reported in the literature can be made consistent with the observed shift in prescription behavior post-LoE. The evolution of a molecule's sales (or market share when total market size is normalized) must be such that:

$$
\frac{\Delta Q}{Q} \simeq \eta_{P} \cdot \frac{\Delta P}{P}+\eta_{A} \cdot \frac{\Delta A}{A}
$$

where $\eta_{P}$ is the price elasticity, and $\eta_{A}$ the advertising elasticity.

Table 4 indicates that generic entry produces an average price drop of about $44-45 \%$ depending on the channel, and an average drop in the flow of promotion between 85 and 90\%. We calculate that, once converted into stocks, these correspond to a drop of respectively $69.4 \%$ and $72.9 \%$ three years after LoE. Taking the pharmacy channel as an example, the predicted change in the market share of the now generic molecule should thus be:

$$
\frac{\Delta Q}{Q} \simeq \eta_{P} \cdot(-0.45)+\eta_{A} \cdot(-0.694)
$$

If we take a lower reasonable bound of $\eta_{P}=1$, and use the estimates for $\eta_{A}$ reported in the meta-analysis by Kremer et al. (2008), it turns out that 55 of the 58 reported elasticities are incompatible with any drop in the molecule's market share, and therefore with actual observations. The same applies for the elasticities reported in Dave and Saffer (2012, Table 2, column 7).

If instead we use our IV-regression results from Table 5, we find that, in hospitals, the predicted change in market share is: $-2.328 \cdot(-0.45)+1.748 \cdot(-0.694)=-0.17$, which compares to an actual average drop of about -0.26 (see Table 4 ). Following the same procedure for pharmacies, the predicted evolution is: $-1.468 \cdot(-0.44)+1.909 \cdot(-0.729)=-0.67$ (actual average drop about -0.31). ${ }^{42}$ Thus, regression results in Table 5 predict $(i)$ a drop in market shares for both segments and $(i i)$ a larger drop for pharmacies. Note that the predicted drop in pharmacies is substantially larger than observed levels. This is compatible with the third party payers' active promotion of generics use.

Beyond this technical point, it should be recalled that the large pharmaceutical corporates

\footnotetext{
${ }^{42}$ With the coefficients of columns 2 and 5 , the predicted drops are -0.15 and -0.88 .
} 
spend $15-20 \%$ of their revenue on promotion in various forms. If detailing were not effective, it would be hard to rationalize such spending by well established and sophisticated firms. Their behavior can only be compatible with profit maximization if advertising elasticities are north of 0.2 in the case of constant returns to promotional effort, or significantly higher in the presence of steeply increasing marginal cost of detailing $(M C \gg A C)$. Berndt et al. 2003), and Manchanda, Rossi and Chintagunta (2004) provide convincing evidence of such fast decreasing returns to detailing, and Chressanthis et al. (2014) document that detailing agents face increasing difficulties to access physicians.

\section{Conclusions and Welfare Implications}

This paper analyzes the consequences of generic entry on on-patent drugs. Our research question was prompted by the puzzling observation that intense intra-molecular price competition following generic entry typically does not lead to increased volume sales for the molecule that experiences Loss of Exclusivity ( $\mathrm{LoE})$. We posit that what drives the aforementioned outcome is the importance of detailing and other forms of promotion combined with an asymmetry in the competitive shock associated with generic entry. Our model shows that a product selling at much reduced price-cost margins may end up selling less, simply because the firm hit by stiffer competition largely stops promoting its product.

This phenomenon helps explain why, despite generics accounting for $75-90 \%$ of the market for the molecules that have lost exclusivity, their overall effect on the market has fallen short of expectations. Legislators and purchasers on both sides of the Atlantic have had to actively promote generic penetration, and yet expenditures on drugs kept on rising.

Our model identifies the circumstances under which the molecule facing generic entry should experience a market share drop. This is when the market is large, the price elasticity of demand is low and, strikingly, when horizontal product differentiation is limited. These theoretical predictions are confirmed by our empirical analysis.

Going one step further, the model allows us to make some inferences regarding allocative efficiency and patient/consumer surplus. Following the logic in Inderst and Ottaviani (2012), our model reckons that promotion does influence physicians' prescription behavior, even when 
it does not directly enter patients' utility. We find that a sufficient condition for patient (consumer) surplus to increase after generic entry is that the market share of molecules remaining on patent decreases in equilibrium (the price and promotion then falls for both molecules). As we saw, this condition is rarely met in practice, meaning that asymmetric competition typically hurts patients according to that definition of surplus. The model also allows us to assess when the change in market shares produced by generic entry brings the market allocation closer to the first best. The answer is never, and a ban on promotion would not solve the problem (Proposition 5 in Appendix 4).

As we argued in the introduction, these mechanisms are still poorly understood today. Yet, regulation and market interventions did evolve since the early 2000s. In recent years, US Third Party Payers (TPPs) started providing increasingly high-powered incentives to promote generic use. For instance, it is now common for insured patients to face higher copayments for on-patent drugs when generics are available. In Europe, generic use has been encouraged by social security systems, with varying degrees of success.

Our model and empirical results provide a rationale for the extent of TPP activism over the last two decades: it is an endogenous response to the strategies implemented by originators. We show that generic entry alone is typically insufficient to contain expenditure in large and profitable therapeutic markets. Hence, additional incentives and constraints on prescription behavior are necessary to actually deliver savings.

Still, the extent to which the prescribing behavior by some private practice physicians can be made responsive to these efforts is an open question. Moreover, we note that in the case of biologics, TPPs activism is bound to be much less effective, as bio-similars are not considered as direct substitutes. Under these circumstances, doctors' discretionary choices will remain central. It is not unreasonable to think that detailing and other types of corporate spending directed at the medical profession will continue to be a key determinant of prescription behavior. 


\section{References}

Aitken, M., L., Berndt, E. R., and Cutler, D., M. (2009). "Prescription Drug Spending Trends In The United States: Looking Beyond The Turning Point", Health Affairs 28, no.1: w151-w160

Aitken, M., L., Berndt, E. R., Bosworth, B., Cockburn I. M., Frank, R., Kleinrock, M. and Shapiro, B. (2013). "The Regulation of Prescription Drug Competition and Market Responses: Patterns in Prices and Sales Following Loss of Exclusivity". NBER Working Paper 19487.

Apple (2013). UNITED STATES SECURITIES AND EXCHANGE COMMISSION, Form 10-K, September 28. http://investor.apple.com/secfiling.cfm?filingid=1193125-13416534\&cik=\#D590790D10K_HTM_TOC590790_1

Arellano, M. and Bover, O. (1995). "Another look at the instrumental-variable estimation of error-components models". Journal of Econometrics, 68, pp. 29-52

Berndt, E.R. (2002). "Pharmaceuticals in U.S. Health Care: Determinants of Quantity and Price". Journal of Economic Perspectives, Vol. 16(4), pp. 45-66.

Berndt, E.R. and Dubois P. (2016). "Impacts of Patent Expiry of Pharmaceutical Treatments in Eight OECD Countries, 2004-2010". International Journal of the Economics of Business, vol. 23(2):125-147.

Berndt, E.R., Kyle, M., and Ling, D. (2003). "The Long Shadow of Patent Expiration: Generic Entry and Rx-to-OTC Switches," in Scanner Data and Price Indexes, ed. R. Feenstra and M. Shapiro University of Chicago Press, pp. 229-267

Berndt, E.R., Pindyck, R and Azoulay, P. (2003) "Consumption Externalities and Diffusion in Pharmaceutical Markets: Antiulcer Drugs". The Journal of Industrial Economics, vol. $51(2): 243-270$.

Branstetter, L.G., Chatterjee C. and Higgins M.J. (2011). "Regulation and Welfare: Evidence from Paragraph IV Generic Entry in the Pharmaceutical Industry". NBER Working Paper No. 17188

Branstetter L.G., Chatterjee, C. and Higgins M.J. (2014). "Starving (or Fattening) the Golden Goose? Generic Entry and the Incentives for Early-Stage Pharmaceutical Innovation". NBER Working Paper 20532.

Brekke, K., Kuhn, M. (2006). "Direct to Consumer Advertising in Pharmaceutical Markets". Journal of Health Economics, 5(1), 102-130.

Caves, R.E., Whinston, M.D., and Hurwitz, M.A. (1991). "Patent expiration, entry, and competition in the U.S. Pharmaceutical Industry". Brookings papers on Economic Activity: Microeconomics, pp. 1-23

Chaudhuri, S., Goldberg, P. K., and Gia, P. (2006). "Estimating the Effects of Global Patent Protection in Pharmaceuticals: A Case Study of Quinolones in India". The American 
Economic Review, Vol. 96(5): 1477-1514

Ching, A. T., and Ishihara, M. (2012). "Measuring the informative and persuasive roles of detailing on prescribing decisions". Management Science, Vol. 58(7), 1374-1387.

Ching, A. T., Clark, R., Horstmann, I., and Lim, H. (2016). "The effects of publicity on demand: The case of anti-cholesterol drugs". Marketing Science, Vol. 35(1), 158-181.

Chressanthis, G., Sfekas, A., Khedkar, P., Jain, N. and Poddar, P. (2014). "Determinants of pharmaceutical sales representative access limits to physicians". Journal of Medical Marketing, Vol. 14849, pp. 220-243.

Crow, D. (2018-01-04) "Cost of Viagra soars as hundreds of drug prices rise in US," Financial Times. https://www.ft.com/content/21dabb8e-f0d5-11e7-b220-857e26d1aca4

Dave, D. and Saffer H. (2012). "The Impact of Direct-to-Consumer Advertising on Pharmaceutical Prices and Demand". Southern Economic Journal, 79, 1. 97-126.

de Frutos, M.A., Ornaghi C. and Siotis G. (2013). "Competition in the pharmaceutical industry: how do quality differences shape advertising strategies?" Journal of Health Economics, 32, 268-285

Donohue, J.M., Cevasco M. and Rosenthal M.B. (2007). "A Decade of Directto-Consumer Advertising of Prescription Drugs". The New England Journal of Medicine. 357:673-81.

Dorfman, R. and P.O. Steiner (1954). "Optimal advertising and optimal quality". American Economic Review, 44, 826-836.

Dubois, P., and Lasio L.. (2017). "Identifying Industry Margins with Unobserved Price Constraints: Structural Estimation on Pharmaceuticals". mimeo.

Duflos, G. and Lichtenberg F. R.. (2012). "Does competition stimulate drug utilization? The impact of changes in market structure on US drug prices, marketing and utilization". International Review of Law and Economics, 32(1), 95-109.

Elison, S., Cockburn I., Griliches, Z. and Hausman J. (1997). "Characteristics of Demand for Pharmaceutical Products: An Exploration of Four Cephalosporins". RAND Journal of Economics, 28(3), 426-446.

Fischer, M., Albers, S., (2010). "Patient- orPhysician-Oriented Marketing: What Drives Primary Demandfor Prescription Drugs?", Journal of Marketing Research, Vol. XLVII, 103121

Grabowski H., and Kyle, M. (2007). "Generic Competition and Market Exclusivity Periods in Pharmaceuticals". Managerial and Decision Economics 28(4-5), 491-502.

Grabowski H., Long G., and Mortimer R. (2014). "Recent trends in brand-name and generic drug competition". Journal of Medical Economics. 17(3):207-14.

Greenway, T. and Ross, J.S. (2017). "US drug marketing: how does promotion corre- 
spond with health value?". BMJ 357:j1855

Griliches, Z and Hausman A..J. (1986). "Errors in Variables in Panel Data". Journal of Econometrics 31: 93-118.

Griliches, Z. and Mairesse J. (1995). "Production Function: The Search for Indentification". NBER Working Paper, No. 5067

Grochowski Jones, R. and Ornstein, C. (2016). "Matching Industry Payments to Medicare Prescribing Patterns: An Analysis". ProPublica. (The undelying data is avalaible at: https://projects.propublica.org/docdollars/)

Grossman, G.M, Shapiro, C. (1984). "Informative Advertising with Differentiated Products". The Review of Economic Studies, Vol. 51, No. 1 (Jan.), pp. 63-81

Harrington, S.E. (2012). "Cost of Capital for Pharmaceutical, Biotechnology, and Medical Device Firms". Oxford Handbook of the Economics of the Biopharmaceutical Industry.

Hotelling, H. (1929). "Stability in Competition", The Economic Journal 39, 41-57

Huckfeldt P. J. and Knittel C.R. (2011). "Pharmaceutical use following generic entry: paying less and buying less". NBER Working Paper 17046.

Hurwitz, M.A. and Caves, R. E. (1988). "Persuasion or Information? Promotion and the Shares of Brand Name and Generic Pharmaceuticals". Journal of Law and Economics 31, No. 2, 299-320

Iizuaka, T. (2004). "What Explains the Use of Direct-to-Consumer Addvertising of Prescription Drugs?", Journal Economics and Management Strategy Vol. 14(3))

Iizuaka, T., Zhe Jin, G. (2005). "The Effect of Prescription Drug Advertising on Doctors Visits", The Journal of Industrial Economics Vol. LII(3)

Iizuaka, T. (2012). "Physician Agency and Adoption of Generic Pharmaceuticals", American Economic Review 102(6), 2826-2858

Inderst, R., and Ottaviani, M. (2012). "Competition through Commissions and Kickbacks". American Economic Review, 102(2): 780-809.

JAMA (2017). "Conflict of Interest Theme Issue", Journal of the American Medical Association, 317(17), May, 1707-1812

Kenkel, D. and Mathios, A. (2012). "Promotion to Physicians and Consumers", in Danzon and Nicholson (eds) Oxford Handbook of the Economics of the Biopharmaceutical Industry.

Klemperer, P. (1987). "Markets with consumer switching costs," The Quarterly Journal of Economics, 102(2), 375-394.

Kremer, S., Bijmolt, T., Leeflang, P., Wieringa, J. (2012). "Generalizations on the effectiveness of pharmaceutical promotional expenditures". International Journal of Research 
in Marketing, 25, 234-246.

Lakdawalla, D., T. Philipson, R. Wang (2007) "Intellectual Property and Marketing", AEI-BROOKINGS JOINT CENTER FOR REGULATORY STUDIES, Working Paper 0720 .

Lakdawalla, D, and Philipson, T. (2012). "Does Intellectual Property Restrict Output? An Analysis of Pharmaceutical Markets". Journal of Law and Economics, 55(1): 151-187.

Manchanda, P., Rossi, P.R. and Chintagunta, P.K. (2004). "Modelling with Nonrandom Marketing-Mix Variables". Journal of Marketing Reserach, 41(4), pp. 467-478.

Mizik, N. and Jacobson, R. (2004). "Are Physicians "Easy Marks"? Quantifying the Effects of Detailing and Sampling on New Prescriptions". Management Science, 50(12): 1704-1715.

Narayanan, S. and Manchanda, P. (2009). "Heterogeneous Learningand the Targeting of Marketing Communication for New Products". Maarketing Science, 28(3) pp.427-441.

Regan, T.L. (2008). "Generic entry, price competition, and market segmentation in the prescription drug market". International Journal of Industrial Organization, 26, 930-948.

Rizzo, J. (1999). "Advertising and competition in the ethical pharmaceutical industry: The case of antihypertensive drugs". Journal of Law and Economics, 42(1) 89-116.

Roodman, D. (2006). "How to Do xtabond2: An Introduction to "Difference" and "System" GMM in Stata". Centre for Global Development, Working paper 103.

Scott Morton, F. M. (2000). "Barriers to entry, brand advertising, and generic entry in the US pharmaceutical industry" International Journal of Industrial Organization 18(7), 1085-1104.

Shaked, A. and J. Sutton (1982). "Relaxing Price Competition Through Product Differentiation", The Review of Economic Studies, 49(1), 3-13.

Stern, S. (1996). "Market Definition and the Returns to Innovation: Substitution Patterns in Pharmaceutical Markets," mimeo.

Vandoros, S. and P. Kanavos (2013). "The generics paradox revisited: empirical evidence from regulated markets". Applied Economics, 45:22, 3230-3239

Venkataraman, S., and Stremersch, S. (2007). "The debate on influencing doctors' decisions: are drug characteristics the missing link?". Management Science, 53(11), 16881701. 


\section{Appendix 1. Benchmark: generic entry in the absence of promotion}

This section presents the case in which firms cannot use detailing and can compete only on prices. One of the main reasons for promoting generics is to make drugs more affordable. The expectation is two-pronged: first, the entry of a generic version of molecule $A$ should put substantial pressure on the price of molecule $A$. As we saw in Section 2, this effect is unquestionably present. Thus, we assume that generic entry does produce such strong competition on molecule $A$ that the price of drug $A$ drops to the marginal cost of production, which we normalized to 0 . This is the direct effect of generic entry.

The second, indirect, effect is the price reaction of firm $B$. We can check how each of these effects operates when firms can compete only on prices-that is when we impose that firms cannot use promotion: $a_{A}=a_{B} \equiv 0$.

Deriving firms' respective reaction functions is straightforward:

$$
\begin{aligned}
& p_{A}=\frac{1}{2 \delta}\left(e-\Delta \theta_{B}+\delta p_{B}\right) \\
& p_{B}=\frac{1}{2 \delta}\left(e+\Delta \theta_{B}+\delta p_{A}\right) .
\end{aligned}
$$

Hence, in the pre-entry equilibrium,

\section{Pre-entry benchmark:}

Before generic entry and in the absence of detailing, for $\theta_{A}+\theta_{B}>2 e$, and $\left|\Delta \theta_{B} / e\right| \leq 3$, the equilibrium is such that:

$$
\begin{aligned}
& p_{A}=\frac{1}{\delta}\left(e-\frac{\Delta \theta_{B}}{3}\right) \text { and } Q_{A}=\left(1-\frac{\Delta \theta_{B}}{3 e}\right) \times \frac{\mu}{2}, \\
& p_{B}=\frac{e}{\delta}+\frac{\Delta \theta_{B}}{3 \delta} \text { and } Q_{B}=\left(1+\frac{\Delta \theta_{B}}{3 e}\right) \times \frac{\mu}{2} .
\end{aligned}
$$

The drug with highest quality $\theta_{J}$, sells more and at a higher price. Moreover, both prices increase in patient heterogeneity $e$ and decrease in price elasticity, $\delta$.

In that benchmark, the condition $\theta_{A}+\theta_{B}>2 e$ is necessary and sufficient to ensure that all patients obtain their treatment in equilibrium. For lower values of $\theta_{J}$, some patients would find both treatments unaffordable. Note that this condition does not depend on price sensitivity $\delta$ because, in the absence of price constraints, firms vary their price exactly to compensate a variation in price sensitivity. In other words, if health insurances double their intervention, total prices will double as well, and the patient will pay the same final price. Second, the condition $\left|\Delta \theta_{B} / e\right| \leq 3$ ensures that both firms sell positive quantities for the price levels derived in benchmark 1.

Upon generic entry, the price of $A$ falls to 0 . As a consequence, by (10), the equilibrium becomes:

Post-entry benchmark:

After generic entry and in the absence of detailing, an interior equilibrium is such that:

$$
\begin{aligned}
& p_{A}=0 \text { and } Q_{A}=\left(\frac{3}{2}-\frac{\Delta \theta_{B}}{2 e}\right) \times \frac{\mu}{2}, \\
& p_{B}=\frac{e+\Delta \theta_{B}}{2 \delta} \text { and } Q_{B}=\left(\frac{1}{2}+\frac{\Delta \theta_{B}}{2 e}\right) \times \frac{\mu}{2} .
\end{aligned}
$$

Note that for any interior solution (i.e., for $0<\Delta \theta_{B} / e<3$ ), the price of $B$ must decrease, and the market share of $A$ must increase in comparison to the pre-entry benchmark. Hence, the only question is the magnitude of this change: the more vertically superior is molecule $B$, the less generic entry influences market shares and equilibrium prices. 


\section{Appendix 2. Empirical Test of Result 1}

Here, we test the initial prediction of Section 3, which identifies key correlations that should result from the strategic interactions among firms when they still benefit from exclusivity.

Based on Result 1, we expect that a producer with a higher-quality molecule will $(a)$ sell more, $(b)$ charge a higher price, and $(c)$ promote its molecule more intensely than its lower-quality competitors. In addition, $(d)$ both promotional effort and price should be decreasing in price sensitivity $\delta$. In light of the differences in price elasticities identified in Section 5.1, we expect lower prices in hospitals than in pharmacies. Last, (e) prices should be increasing in the degree of "horizontal differentiation", as defined in Section 4.

Empirically, predictions $(a-c)$ compare different molecules/firms in a particular market. However, we cannot directly observe the relative quality or other differences between molecules. Hence, we use a specification in first-differences to test whether an increase in market share is, indeed, associated with higher promotion and prices. Firm $i$ 's behavior in market $j$ at quarter $t$ is described by the following equation:

$$
\Delta y_{i, t}=\beta_{0}+\beta_{1} \Delta q_{i, t}+\beta_{2} H o s p+\beta_{3} M o A_{j, t}+X_{i, t}+\varepsilon_{i, t},
$$

where, based on equation (5) (resp. (6)) in Section 3.1, $y$ is price (resp. promotion) and $q$ is market share (resp. quantity). Hosp is a dummy taking value 1 for the hospital channel and zero otherwise. Mo $A_{j, t}$ has been defined above, and the control variables $X$ include a trend that identifies the number of quarters before patent expiration of brand $i$ (time to expiration, $T E$ ), and a complete set of time dummies. As in Section 5.1, we focus on branded drugs until one quarter before LoE.

\begin{tabular}{|c|c|c|c|c|c|}
\hline & $\begin{array}{c}\text { Dep. Variable: } \\
\text { Coeff. }\end{array}$ & $\begin{array}{l}\text { Promotion } \\
\operatorname{FD}(1)\end{array}$ & $\begin{array}{c}\text { Promotion } \\
\operatorname{FD}(2)\end{array}$ & $\begin{array}{l}\text { Price } \\
\operatorname{FD}(3)\end{array}$ & $\begin{array}{c}\text { Price-IV } \\
\operatorname{FD}(4) \\
\end{array}$ \\
\hline Quantity & $\beta_{1 q}$ & $\begin{array}{c}0.251^{* * *} \\
(0.054)\end{array}$ & & & \\
\hline Market-Shares & $\beta_{1 m s}$ & & & $\begin{array}{c}-0.037^{* * *} \\
(0.008)\end{array}$ & $\begin{array}{c}0.038^{* *} \\
(0.020)\end{array}$ \\
\hline Price & $\beta_{1 p}$ & & $\begin{array}{c}0.339^{* *} \\
(0.184)\end{array}$ & & \\
\hline Hospital & $\beta_{2}$ & $\begin{array}{l}-0.006 \\
(0.005)\end{array}$ & $\begin{array}{l}-0.001 \\
(0.004)\end{array}$ & $\begin{array}{c}-0.003^{* * *} \\
(0.001)\end{array}$ & $\begin{array}{c}-0.005^{* * *} \\
(0.002)\end{array}$ \\
\hline Modes of Action: " $e$ " & $\beta_{3}$ & $\begin{array}{l}-0.070 \\
(0.061)\end{array}$ & $\begin{array}{l}-0.067 \\
(0.058)\end{array}$ & $\begin{array}{c}-0.006^{* *} \\
(0.003)\end{array}$ & $\begin{array}{l}-0.003 \\
(0.004)\end{array}$ \\
\hline Time to Expiration & & $\begin{array}{l}-0.001 \\
(0.001)\end{array}$ & $\begin{array}{c}-0.002^{* *} \\
(0.001)\end{array}$ & $\begin{array}{l}-0.001 \\
(0.001)\end{array}$ & $\begin{array}{c}0.001^{* * *} \\
(0.000)\end{array}$ \\
\hline $\begin{array}{l}\text { Observations } \\
\text { R-squared }\end{array}$ & & $\begin{array}{c}10345 \\
235\end{array}$ & $\begin{array}{c}10345 \\
228\end{array}$ & 10345 & 10345 \\
\hline $\begin{array}{l}\text { R-squared } \\
\text { Under-identification }^{a} \\
\text { Hansen J-test }(\mathrm{df})^{b}\end{array}$ & & .235 & .228 & .050 & $\begin{array}{c}<0.001 \\
0.438(1)\end{array}$ \\
\hline
\end{tabular}

Notes: Robust standard errors clustered at ATC3-market level in parentheses. * significant at $10 \%$ level; ** significant at 5\%; *** significant at 1\%. In Model (4), we control for endogeneity of price using promotion and number of competitors as demand shifters. ${ }^{a} \mathrm{P}$-values of F-test for excluded instruments in the first stage. ${ }^{b} \mathrm{P}$-value of Hansen J-test of overidentification.

Table 7. Market Share, Price and Promotion under Patent Protection

The results are reported in Table 7. Specification (3) in the table suffers from the classic identification problem that both demand and supply influence that relationship. To address this issue, we exploit the results 
in Section 5.1, which showed that promotion produces an outward shift of demand. Therefore, in column (4), we use promotion as an instrument to isolate supply-side effects.

In line with Result 1, we find that prices, promotion and market shares co-move positively over time. ${ }^{43}$ Next, the price response is lower in hospitals (prediction $d$ ), although the effect for promotion is not significant. In line with the theoretical model, $e$ does not directly influence promotion. However, in contrast with our predictions, we do not find a significant impact of $e$ on price. The reason is probably that most of the data variation for Modes of Action comes from differences across markets and not over time. ${ }^{44}$

\section{Appendix 3. Equilibrium before and after generic entry}

Here, we derive the explicit solutions for the equilibrium levels of prices, promotion, and quantities before and after generic entry. We work under the following condition, which ensures that solutions are interior (i.e., the market share of $A$ before entry is strictly positive):

Condition $1 \mu<\left(3 e-\Delta \theta_{B}\right) \delta$ or, equivalently: $\Delta \theta_{B}<3 e-\mu / \delta$.

Before generic entry.

Letting $K_{J} \equiv 1+\frac{\theta_{J}-\theta_{-J}}{3 \delta e-\mu} \delta$ and solving explicitly yields:

Proposition 2 Under Condition 1, the equilibrium prior to generic entry is unique and such that:

$$
\begin{aligned}
p_{J}^{D} & =\frac{e}{\delta} K_{J} \\
a_{J}^{D} & =\frac{\mu}{2 \delta} K_{J} \\
Q_{J}^{D} & =\frac{\mu}{2} K_{J},
\end{aligned}
$$

for $J \in\{A, B\}$. Hence, the most advanced molecule, $B$, has a higher price, advertisement level and market share than $A$.

Proof. Everything follows directly from the FOCs:

$$
\begin{aligned}
& \frac{\partial \pi_{A}}{\partial a_{A}}=\frac{\mu p_{A}}{2 e}-a_{A}=0 \\
& \frac{\partial \pi_{B}}{\partial a_{B}}=\frac{\mu p_{B}}{2 e}-a_{B}=0 .
\end{aligned}
$$

Hence:

$$
\Delta a_{B}=\frac{\mu}{2 e} \Delta p_{B}
$$

Next:

$$
\begin{aligned}
& \frac{\partial \pi_{A}}{\partial p_{A}}=\left[\frac{1}{2}-\frac{\Delta \theta_{B}+\Delta a_{B}-\delta\left(p_{B}-2 p_{A}\right)}{2 e}\right] \times \mu=0 \Leftrightarrow p_{A}=\frac{e}{\delta}\left[\frac{1}{2}-\frac{\Delta \theta_{B}+\mu \frac{p_{B}-p_{A}}{2 e}-\delta p_{B}}{2 e}\right] \\
& \frac{\partial \pi_{B}}{\partial p_{B}}=\left[\frac{1}{2}+\frac{\Delta \theta_{B}+\Delta a_{B}-\delta\left(2 p_{B}-p_{A}\right)}{2 e}\right] \times \mu=0 \Leftrightarrow p_{B}=\frac{e}{\delta}\left[\frac{1}{2}+\frac{\Delta \theta_{B}+\mu \frac{p_{B}-p_{A}}{2 e}+\delta p_{A}}{2 e}\right]
\end{aligned}
$$

\footnotetext{
${ }^{43}$ In column (3), we observe that the demand side of the ledger dominates the raw correlation between prices and market shares. Once market shares are properly instrumented for in column (4), the coefficient changes sign and is precisely estimated.

${ }^{44}$ Only 10 of the 53 ATC3 markets register an increase in the number of Modes of Action during the time window we consider.
} 
Solving jointly for $p_{A}$ and $p_{B}$ yields:

$$
\begin{aligned}
& p_{A}=\frac{e}{\delta}\left(1-\frac{\Delta \theta_{B} \delta}{3 \delta e-\mu}\right) \\
& p_{B}=\frac{e}{\delta}\left(1+\frac{\Delta \theta_{B} \delta}{3 \delta e-\mu}\right)
\end{aligned}
$$

Finally, Condition 1 follows from the fact that $Q_{A} \geq 0$ iff:

$$
\begin{aligned}
1 & \geq \frac{\Delta \theta_{B}+\Delta a_{B}-\delta\left(p_{B}-p_{A}\right)}{e} \\
e & \geq \Delta \theta_{B}+\frac{\mu}{2 e} 2 \frac{e}{\delta} \frac{\Delta \theta_{B} \delta}{3 \delta e-\mu}-2 \delta \frac{e}{\delta} \frac{\Delta \theta_{B} \delta}{3 \delta e-\mu} \\
\frac{e}{\Delta \theta_{B}} & \geq 1+\frac{\mu}{3 \delta e-\mu}-\frac{2 \delta e}{3 \delta e-\mu}=\frac{3 \delta e-\mu+\mu-2 e \delta}{3 \delta e-\mu}=\frac{\delta e}{3 \delta e-\mu} \\
\Delta \theta_{B} & \leq \frac{3 \delta e-\mu}{\delta}
\end{aligned}
$$

After generic entry.

Profit maximization yields:

Proposition 3 Post generic entry, the unique equilibrium is given by:

$$
\begin{aligned}
p_{A}^{G} & =a_{A}^{G}=0 \\
p_{B}^{G} & =2 e \frac{\Delta \theta_{B}+e}{4 \delta e-\mu} \\
a_{B}^{G} & =\frac{\mu}{2 e} p_{B}^{G} \\
Q_{B}^{G} & =\frac{\mu}{2}\left[1+\frac{2 \delta \Delta \theta_{B}-(2 \delta e-\mu)}{4 \delta e-\mu}\right]
\end{aligned}
$$

Proof. Perfect competition amongst generics implies that $p_{A}=a_{A}=0$. Taking first-order conditions of the maximization of $\pi_{B}$ with respect to $p_{B}$ and $a_{B}$ yields the Proposition.

\section{Appendix 4. Outcome efficiency and patient surplus}

The results in Section 3.2 can be exploited to analyze how generic entry influences static allocative efficiency and patient (consumer) surplus. The fact that our results focus on static efficiency is important to note: our analysis considers firm behavior for pre-existing molecules, around the time of patent expiration. As we know, patents are essential to provide the incentives to pharmaceutical firms to develop these molecules in the first place. Yet, extending the analysis to dynamic allocative efficiency and welfare would require accounting for the endogenous R\&D investments by different firms, which is beyond the scope of this paper.

Keeping this in mind, static efficiency is reached when both firm $A$ and $B$ face perfect competition. In this first-best case $(F B)$, the price of both molecules is driven down to marginal costs, $p_{A}^{F B}=p_{B}^{F B}=0$, and promotion consequently drops to zero: $a_{A}^{F B}=a_{B}^{F B}=0$. The resulting quantities are:

$$
Q_{J}^{F B}=\frac{\mu}{2}\left(1+\frac{\Delta \theta_{J}}{e}\right),
$$

and patient/consumer surplus is maximized. 
Quite trivially, we would reach first best as soon as all molecules have lost exclusivity; it is just a matter of time. In reality, new vintages of old treatments (so-called "me too" drugs) and new treatments appear constantly. In our quarterly data, for instance, there is at least one molecule still under patent protection for all "anatomic therapeutic classes" and periods. That is, reality is best described either by situation $D$ or situation $G$ that we analyzed above. Our purpose here will be to identify when the movement from $D$ (only patent-protected molecules) to $G$ (some patent-protected molecules) improves market efficiency and/or consumer surplus. We find that:

Proposition 4 Whether a pharmaceutical firm can (D), or cannot (ND), use detailing, generic entry never brings the market equilibrium closer to the first-best allocation (16).

Proof. First, let us concentrate on the case in which firms can use detailing and focus on the quantities sold by $B$, since $A$ serves the rest of the market. Consider, first, the case in which $q_{B}^{D}>q_{B}^{F B}-i . e$., $B$ sells too much prior to generic entry. By (14) and (16) this only happens if:

$$
\frac{\delta}{3 \delta e-\mu}>\frac{1}{e} \Leftrightarrow 2 \delta e<\mu,
$$

which is the exact condition in Proposition 1 for $q_{B}^{G}>q_{B}^{D}$. Hence, generic entry produces an increase in the quantities sold by $B$ precisely when convergence to the first best requires a drop. By the same token, the reverse is true for $2 \delta e>\mu$.

Second, let us turn to the case in which firms cannot use detailing. As shown in Appendix 1, the quantities before and after generic entry are, respectively:

$$
\begin{aligned}
Q_{B}^{D} & =\frac{\mu}{2}\left(1+\frac{\Delta \theta_{B}}{3 e}\right) \\
Q_{B}^{G} & =\frac{\mu}{4}\left(1+\frac{\Delta \theta_{B}}{e}\right)=\frac{Q_{B}^{F B}}{2},
\end{aligned}
$$

and the condition for $Q_{B}^{D}$ and $Q_{B}^{G}$ to be less than the whole market $(\mu)$ is: $\Delta \theta_{B}<3 e$. It is straightforward to check that, for such parameter values, we always have $Q_{B}^{G}<Q_{B}^{D}<Q_{B}^{F B}$.

The main reason for this result is the same as for Proposition 1: generic entry produces a very asymmetric type of competition, in which one molecule becomes cheaper but is no longer promoted and the other remains protected against direct competition. As we saw, when molecules are distant substitutes and/or market size is small $(2 \delta e>\mu)$, the genericization of $A$ intensifies competition for $B$, which loses market share, and cuts down prices and promotion as a result. This is exactly the intended purpose of generic competition. The problem is that this happens precisely when B's market share is initially lower than in the first best.

Conversely, when the two molecules are close substitutes and/or market size is large $(2 \delta e<\mu)$, the genericization of $A$ actually relaxes the competitive pressure on $B$. This allows firm $B$ to actually gain market power and market share. In this case, firm $B$ also grabs the opportunity to increase its prices and its detailing effort. This only happens when $B$ 's market share was already initially too high.

Interestingly, prohibiting detailing altogether would not be a panacea. In that case, the market share of the more advanced molecule $B$ is always too low (except in the corner solutions in which it grabs $100 \%$ of the market), and the genericization of $A$ further reduces it.

From a policy perspective, being confronted with explosive expenditures on healthcare, authorities have actively promoted the use of generics, partly in an effort to contain the costs borne (directly or indirectly) by patients. In addition, competition authorities have, de facto, adopted a consumer surplus standard. We define consumer surplus as their utility minus the price they pay for the molecule they actually buy. Importantly, their utility depends on the actual quality of the molecule, $\theta_{J}$, whereas which molecule they actually buy also depends on promotion effort, which is rather targeted at the physicians or is spent on the representatives' wages, etc. Thus, we calculate consumer surplus as the integral of the patients' utilities (1-2) when they 
actually consume the quantities $Q_{J}^{D}$ before, and $Q_{J}^{G}$ after, generic entry. ${ }^{45}$ We find that:

Proposition 5 Generic entry necessarily increases consumer welfare when B's market share (weakly) decreases after generic entry (i.e., for $\mu<2 \delta e$ ). For $\Delta \theta_{B}=0$, consumer surplus decreases upon generic entry when $\mu>\frac{2 \delta e}{3}(7-\sqrt{10}) \simeq 2.56 \delta$, in which case $B$ gains substantial market share, and increases prices and promotion intensity.

Proof. After tedious algebra (see supplementary material), we find that:

$$
2 \delta e=\mu \Rightarrow C W^{G}-C W^{D}=\frac{(e-1)^{2}}{2} \geq 0,
$$

where $C W^{D}$ is consumer surplus when both $A$ and $B$ benefit from patent protection, and $C W^{G}$ is consumer surplus when only $B$ still benefits from patent protection. When $\mu$ is smaller, prices must be decreasing for all consumers, and their welfare increases.

Imposing $\Delta \theta_{B}=0$ for the sake of tractability, one can also identify the value of $\mu$ for which this difference in consumer surplus is zero. The threshold is: $\mu=\frac{2 \delta e}{3}(7-\sqrt{10})$. For any values of $\mu$ below that threshold, consumer surplus increases upon generic entry.

45 The derivations of consumer surplus are available upon request. We do not present them here because they are tedious but rather straightforward. 


\section{Appendix 5: Supplementary tables}

Table A1: list of ATC3 markets

\begin{tabular}{|c|c|c|c|c|c|}
\hline ATC3 & ATC4 & ATC4_name & ATC3 & ATC4 & ATC4_name \\
\hline A10B & A10B1 & Sulphonylurea Antidiabetics & J1D & J1D1 & Cephalosporins,0ral \\
\hline A10B & A10B2 & Biguanide Antidiabetics & $J 1 G$ & J1G1 & Oral Fluoroquinolones \\
\hline A10B & A10B3 & Comb Sulph+Biguan Antidiabetics & $\mathrm{J} 2 \mathrm{~A}$ & $\mathrm{~J} 2 \mathrm{~A} 0$ & Syst Antifungal Agents \\
\hline A10B & $\mathrm{A} 10 \mathrm{~B} 4$ & Thiazolinedione Antidiabetics & $\mathrm{J} 4 \mathrm{~A}$ & J4A1 & Anti-Tb, Single Ingred \\
\hline A10B & A10B5 & Alpha-Gluc.Inhib. Antidiabetics & J5B & J5B0 & Antivirals Excl Anti-Hiv \\
\hline $\mathrm{A} 10 \mathrm{~B}$ & A10B9 & Other Oral Antidiabetics & L1A & L1A0 & Alkylating Agents \\
\hline A2B & A2B1 & H2 Antagonists & L1B & L1B0 & Antimetabolites \\
\hline A2B & A2B2 & Acid Pump Inhibitors & L1C & L1C0 & Vinca Alkaloids \\
\hline $\mathrm{A} 2 \mathrm{~B}$ & A2B 9 & All Other Antiulcerants & L1D & L1D0 & Antineoplas. Antibiotics \\
\hline B1C & B1C2 & Adp Recep Antag Plat Inhibitors & L1X & L1X1 & Adj Prep For Cancer Ther \\
\hline B1C & B1C4 & Pl Camp Enh Plat Ag Inhibitors & L1X & L1X2 & Platinum Compounds \\
\hline C10A & C10A1 & Statins - Hmg-Coa Reduct. Inhibitors & L1X & L1X9 & All Oth. Antineoplastics \\
\hline C10A & C10A3 & Bile Acid Sequestrant & L2B & L2B1 & Cyto Anti-Oestrogens \\
\hline C10A & C10A9 & All 0th Chol/Triglyc Red & L2B & L2B2 & Cyto Anti-Androgens \\
\hline C1B & C1B0 & Antiarrhythmics & L2B & L2B3 & Cytostat Aromatase Inhibitors \\
\hline $\mathrm{C} 1 \mathrm{~F}$ & C1F0 & Positive Inotropic Agent & L4A & L4A0 & Immunosuppressive Agents \\
\hline C1X & C1X0 & All 0ther Cardiac Preps & M1A & M1A1 & Antirheumatics Non-S Pln \\
\hline $\mathrm{C} 2 \mathrm{~A}$ & C2A1 & Antihyper.Pl Mainly Cent & M1A & M1A3 & Coxibs \\
\hline $\mathrm{C} 2 \mathrm{~A}$ & $\mathrm{C} 2 \mathrm{~A} 2$ & Antihyper.Pl Mainly Peri & M1C & M1C0 & Spec Antirheumatic Agent \\
\hline C3A & C3A2 & Loop Diuretics Plain & M5B & M5B1 & Oral Bisph Bone Calc Reg \\
\hline $\mathrm{C} 3 \mathrm{~A}$ & С3А & Thiazide+Analogue Plain & $\mathrm{N} 1 \mathrm{~A}$ & N1A2 & Inject Gen Anaesthetics \\
\hline $\mathrm{C} 4 \mathrm{~A}$ & C4A1 & Cereb/Periph Vasotheraps & $\mathrm{N} 2 \mathrm{~A}$ & $\mathrm{~N} 2 \mathrm{~A} 0$ & Narcotic Analgesics \\
\hline C7A & C7A0 & B-Blocking Agents,Plain & $\mathrm{N} 2 \mathrm{~B}$ & N2B0 & Non-Narcotic Analgesics \\
\hline $\mathrm{C} 8 \mathrm{~A}$ & C8A0 & Calcium Antagonist Plain & N3A & N3A0 & Anti-Epileptics \\
\hline C9A & $\mathrm{C} 9 \mathrm{~A} 0$ & Ace Inhibitors Plain & N4A & N4A0 & Anti-Parkinson Preps \\
\hline C9B & C9B1 & Ace Inhibitors Comb+A-Hyp/Diur & N5A & N5A1 & Atypical Antipsychotics \\
\hline C9B & С9B3 & Ace Inhibitors Comb+Calc Antag & N5B & N5B1 & Non-Barbiturate Plain \\
\hline D10A & $\mathrm{D} 10 \mathrm{~A} 0$ & Topical Anti-Acne Preps & N5C & $\mathrm{N} 5 \mathrm{C} 0$ & Tranquillisers \\
\hline D11A & $\mathrm{D} 11 \mathrm{~A} 0$ & Other Dermatological Prd & N6A & N6A1 & Antidepress.Excl Herbals \\
\hline D1A & D1A1 & Topical Dermat Antifung & N6B & N6B0 & Psychostimulants \\
\hline D6D & D6D1 & Topical Antivirals & P1D & P1D1 & Antimalarials Single Ing \\
\hline D6D & D6D9 & Oth Top Prds Viral Inf & R1A & R1A1 & Nasal Cortic W/0 Anti-inf \\
\hline D7A & D7A0 & Top.Corticosteroid Plain & R1A & R1A6 & Nasal A-Allergic Agents \\
\hline G4A & G4A1 & Urinary Antibiot/Sulphon & R1B & R1B0 & Systemic Nasal Preps \\
\hline G4B & G4B3 & Erectile Dysfunction Prd & R3G & R3G4 & A-Chol+B2-Stim Comb,Inh \\
\hline G4B & G4B4 & Urinary Incontinence Prd & R6A & R6A0 & Antihistamines Systemic \\
\hline G4B & G4B9 & All 0th Urological Prods & S1D & S1D0 & Anti-Viral Agents -Eye \\
\hline $\mathrm{J} 1 \mathrm{C}$ & $\mathrm{J} 1 \mathrm{C} 1$ & Brd.Spect.Penicill.Oral & & & \\
\hline
\end{tabular}


TABLE A2: List of Branded Drugs losing patent protection

\begin{tabular}{|c|c|c|}
\hline Brand Name & Generic Name & Quarter Generic Entry \\
\hline anafranil & clomipramine & $1996 q 4$ \\
\hline ansaid & flurbiprofen & $1994 q 2$ \\
\hline augmentin & amoxicillin+clavulanic acid & $2002 q^{3}$ \\
\hline axid & nizatidine & $2001 q 3$ \\
\hline betapace & sotalol & $2000 q 2$ \\
\hline blenoxane & bleomycin & $1996 q^{3}$ \\
\hline bumex & bumetanide & $1995 q 1$ \\
\hline buspar & buspirone & $2001 q 2$ \\
\hline capoten & captopril & $1995 q 4$ \\
\hline capozide & captopril+hydrochlorothiazide & $1997 q 4$ \\
\hline carafate & sucralfate & $1996 q 4$ \\
\hline cardene & nicardipine & $1996 q 3$ \\
\hline cardura & doxazosin & $2000 q 4$ \\
\hline ceclor & cefaclor & $1994 q 4$ \\
\hline cerubidine & daunorubicin & $1998 q 2$ \\
\hline ciproxin & ciprofloxacin & $2003 q 2$ \\
\hline clarinase & loratadine+pseudoephedrine & $2002 q^{3}$ \\
\hline claritine & loratadine & $2002 q 3$ \\
\hline condylox & podofilox & $2002 q 1$ \\
\hline cordarone & amiodarone & $1998 q 2$ \\
\hline cyclocort & amcinonide & $2002 q 2$ \\
\hline cylert & pemoline & $1999 q 2$ \\
\hline daypro & oxaprozin & $2001 q 1$ \\
\hline diprivan & propofol & $1999 q 2$ \\
\hline dormicum & midazolam & $2000 q 2$ \\
\hline drogenil & flutamide & $2001 q^{3}$ \\
\hline dtic-dome & dacarbazine & $1998 q 4$ \\
\hline duricef & cefadroxil & $1996 q 1$ \\
\hline eldepryl & selegiline & $1996 q 3$ \\
\hline elocon & mometasone & $2002 q 1$ \\
\hline floxstat & ofloxacin & $2003 q^{3}$ \\
\hline floxyfral & fluvoxamine & $2000 q 4$ \\
\hline glucophage & metformin & $2002 q 1$ \\
\hline glucotrol & glipizide & $1994 q 2$ \\
\hline heitrin & terazosin & $1999 q^{3}$ \\
\hline imuran & azathioprine & $1995 q^{3}$ \\
\hline inocor & amrinone & $1998 q^{3}$ \\
\hline lariam & mefloquine & $2002 q 2$ \\
\hline leponex & clozapine & $1997 q 4$ \\
\hline lodine & etodolac & $1997 q 1$ \\
\hline Ioniten & minoxidil & $1996 q 2$ \\
\hline losec & omeprazole & $2002 q 4$ \\
\hline mevacor & lovastatin & $2001 q 4$ \\
\hline mexitil & mexiletine & $1995 q 2$ \\
\hline micronase & glibenclamide & $1994 q 2$ \\
\hline mutamycin & mitomycin & $1995 q 2$ \\
\hline myambutol & ethambutol & $2000 q 2$ \\
\hline navelbine & vinorelbine & $2003 q 1$ \\
\hline
\end{tabular}




\begin{tabular}{|c|c|c|}
\hline Brand Name & Generic Name & Quarter Generic Entry \\
\hline nizoral & ketoconazole & $1999 q 2$ \\
\hline nolvadex & tamoxifen & $2002 q 4$ \\
\hline normodyne & labetalol & $1998 \mathrm{q} 3$ \\
\hline pepcidine & famotidine & $2001 q 2$ \\
\hline permax & pergolide & $2002 q 4$ \\
\hline pevaryl & econazole & $2002 q 4$ \\
\hline platinol & cisplatin & $1999 q 4$ \\
\hline prostin vr & alprostadil & $1998 \mathrm{q} 1$ \\
\hline prozac & fluoxetine & $2000 q 3$ \\
\hline psorcon & diflorasone & $1998 q 2$ \\
\hline questran & colestyramine & $1996 q 3$ \\
\hline relifex & nabumetone & $2001 q 3$ \\
\hline retin-a & tretinoin & $1998 q 2$ \\
\hline rivotril & clonazepam & $1996 q 3$ \\
\hline rynatan mepo & chlorpheniramine+mepyramine & $1994 q 4$ \\
\hline sandimmun & ciclosporin & $1998 q 4$ \\
\hline sectral & acebutolol & $1995 q 2$ \\
\hline seroxat & paroxetine & $2003 q 3$ \\
\hline serzone & nefazodone & $2003 q 3$ \\
\hline somnatrol & estazolam & $1997 q 3$ \\
\hline stadol & butorphanol & $1997 q 2$ \\
\hline staril & fosinopril & $2003 q 4$ \\
\hline sufenta & sufentanil & $1996 q 1$ \\
\hline tagamet & cimetidine & $1994 q 2$ \\
\hline talwin $\mathrm{nx}$ & naloxone+pentazocine & $1997 q 2$ \\
\hline tambocor & flecainide & $2002 q 1$ \\
\hline taxol & paclitaxel & $2000 q 4$ \\
\hline temovate & clobetasol & $1994 q 3$ \\
\hline tenex & guanfacine & $1995 q 4$ \\
\hline ticlid & ticlopidine & $1999 q 2$ \\
\hline toradol & ketorolac & $1997 q 2$ \\
\hline trental & pentoxifylline & $1997 q 3$ \\
\hline ultram & tramadol & $2002 q 2$ \\
\hline unat & torasemide & $2002 q 2$ \\
\hline univasc & moexipril & $2003 q 2$ \\
\hline vaseretic & enalapril+hydrochlorothiazide & $2001 q 3$ \\
\hline vasotec & enalapril & $2000 \mathrm{q} 3$ \\
\hline viroptic & trifluridine & $1996 q 2$ \\
\hline voltaren & diclofenac & $1995 q 3$ \\
\hline wytensin & guanabenz & $1994 q 3$ \\
\hline zantac & ranitidine & $1997 q 3$ \\
\hline zaroxolyn & metolazone & $2003 q 3$ \\
\hline zavedos & idarubicin & $2002 q 3$ \\
\hline zestoretic & hydrochlorothiazide+lisinopril & $2002 q 2$ \\
\hline zestril & lisinopril & $2002 q 2$ \\
\hline zinnat & cefuroxime axetil & $2002 q 1$ \\
\hline zovirax & aciclovir & $1997 q 2$ \\
\hline
\end{tabular}

